\title{
Widespread deoxygenation of temperate lakes
}

Article

Accepted Version

Jane, S. F., Hansen, G. J. A., Kraemer, B. M., Leavitt, P. R., Mincer, J. L., North, R. L., Pilla, R. M., Stetler, J. T.,

Williamson, C. E., Woolway, R. I. ORCID:

https://orcid.org/0000-0003-0498-7968, Arvola, L., Chandra, S., DeGasperi, C. L., Diemer, L., Dunalska, J., Erina, O., Flaim, G., Grossart, H.-P., Hambright, K. D., Hein, C., Hejzlar, J., Janus, L. L., Jenny, J.-P., Jones, J. R., Knoll, L. B., Leoni, B., Mackay, E., Matsuzaki, S.-i. S., McBride, C., MüllerNavarra, D. C., Paterson, A. M., Pierson, D., Rogora, M., Rusak, J. A., Sadro, S., Saulnier-Talbot, E., Schmid, M., Sommaruga, R., Thiery, W., Verburg, P., Weathers, K. C., Weyhenmeyer, G. A., Yokota, K. and Rose, K. C. (2021) Widespread deoxygenation of temperate lakes. Nature, 594. pp. 66-70. ISSN 0028-0836 doi:

https://doi.org/10.1038/s41586-021-03550-y Available at https://centaur.reading.ac.uk/100084/

It is advisable to refer to the publisher's version if you intend to cite from the work. See Guidance on citing.

To link to this article DOI: http://dx.doi.org/10.1038/s41586-021-03550-y

Publisher: Nature Publishing Group 
All outputs in CentAUR are protected by Intellectual Property Rights law, including copyright law. Copyright and IPR is retained by the creators or other copyright holders. Terms and conditions for use of this material are defined in the End User Agreement.

\section{$\underline{\text { www.reading.ac.uk/centaur }}$}

\section{CentAUR}

Central Archive at the University of Reading

Reading's research outputs online 
1

2 Widespread deoxygenation of temperate lakes

4 Authors:

5 Stephen F. Jane ${ }^{1,2}$, Gretchen J. A. Hansen ${ }^{3}$, Benjamin M. Kraemer ${ }^{4}$, Peter R. Leavitt ${ }^{5,6}$, Joshua L.

6 Mincer $^{1}$, Rebecca L. North ${ }^{7}$, Rachel M. Pilla ${ }^{8}$, Jonathan T. Stetler ${ }^{1}$, Craig E. Williamson ${ }^{8}$, R.

7 Iestyn Woolway ${ }^{9}$, Lauri Arvola ${ }^{10}$, Sudeep Chandra ${ }^{11}$, Curtis L. DeGasperi ${ }^{12}$, Laura Diemer ${ }^{13}$,

8 Julita Dunalska ${ }^{14}$, Oxana Erina ${ }^{15}$, Giovanna Flaim ${ }^{16}$, Hans-Peter Grossart ${ }^{17}{ }^{18}$, K. David

9 Hambright $^{19}$, Catherine Hein ${ }^{20}$, Josef Hejzlar ${ }^{21}$, Lorraine L. Janus ${ }^{22}$, Jean-Philippe Jenny ${ }^{23}$, John

10 R. Jones ${ }^{7}$, Lesley B. Knoll ${ }^{24}$, Barbara Leoni ${ }^{25}$, Eleanor Mackay ${ }^{26}$, Shin-Ichiro S. Matsuzaki ${ }^{27}$,

11 Chris McBride ${ }^{28}$, Dörthe C. Müller-Navarra ${ }^{29}$, Andrew M. Paterson ${ }^{30}$, Don Pierson ${ }^{2}$, Michela

12 Rogora $^{31}$, James A. Rusak ${ }^{29}$, Steven Sadro ${ }^{32}$, Emilie Saulnier-Talbot ${ }^{33}$, Martin Schmid ${ }^{34}$, Ruben

13 Sommaruga ${ }^{35}$, Wim Thiery ${ }^{36,37}$, Piet Verburg ${ }^{38}$, Kathleen C. Weathers ${ }^{39}$, Gesa A.

14 Weyhenmeyer ${ }^{2}$, Kiyoko Yokota ${ }^{40}$, and Kevin C. Rose ${ }^{1}$

1. Department of Biological Sciences, Rensselaer Polytechnic Institute, Troy, NY, USA

2. Department of Ecology and Genetics/Limnology, Uppsala University, Uppsala, Sweden

3. Department of Fisheries, Wildlife and Conservation Biology, University of Minnesota, St. Paul, MN, USA

4. Department of Ecosystem Research, IGB Leibniz institute for freshwater ecology and inland fisheries, Berlin, Germany 
5. Institute of Environmental Change and Society, University of Regina, Regina, Saskatchewan, Canada

6. Institute for Global Food Security, Queen's University Belfast, Belfast, County Antrim, United Kingdom

7. School of Natural Resources, University of Missouri, Columbia, MO, USA

8. Department of Biology, Miami University, Oxford, OH, USA

9. Centre for Freshwater and Environmental Studies, Dundalk Institute of Technology, Dundalk, Ireland

10. Lammi Biological Station, University of Helsinki, Pääjärventie 320, Lammi, Finland 11. Biology Department and Global Water Center, University of Nevada, Reno, NV, USA

12. King County Water and Land Resources Division, Seattle, WA, USA

13. FB Environmental Associates, Portsmouth, NH, USA

14. Department of Water Protection Engineering, University of Warmia and Mazury in Olsztyn, Prawocheńskiego str. 1, Olsztyn, Poland

15. Department of Hydrology, Lomonosov Moscow State University, Leninskiye Gory 1, Moscow, Russia

16. Department of Sustainable Agro-ecosystems and Bioresources, Research and Innovation Centre, Fondazione Edmund Mach, San Michele all'Adige, Italy

17. Department of Experimental Limnology, Leibniz-Institute of Freshwater Ecology and Inland Fisheries, Alte Fischerhuette 2, Stechlin, Germany 
18. Institute of Biochemistry and Biology, Potsdam University, Maulbeerallee 2, Potsdam, Germany

19. Plankton Ecology and Limnology Laboratory, Geographical Ecology Group, and Program in Ecology and Evolutionary Biology, Department of Biology, The University of Oklahoma, Norman, Oklahoma, USA

20. Wisconsin Department of Natural Resources, Madison, WI, USA

21. Institute of Hydrobiology, Biology Centre CAS, Na Sádkách 7, České Budějovice, Czech Republic

22. Bureau of Water Supply, New York City Department of Environmental Protection, 465 Columbus Ave., Valhalla, NY, USA

23. CARRTEL Limnology Center, Institut National de la Recherche Agronomique (INRA), Université Savoie Mont Blanc, 73000 Chambéry, France

24. Itasca Biological Station and Laboratories, University of Minnesota, Lake Itasca, MN, USA

25. Department of Earth and Environmental Sciences, University of Milan-Bicocca, Piazza della Scienza 1, Milan, Italy

26. Lake Ecosystems Group, Centre for Ecology \& Hydrology, Bailrigg, Lancaster, United Kingdom

27. Center for Environmental Biology and Ecosystem Studies, National Institute for Environmental Studies, 16-2 Tsukuba, Ibaraki, Japan

28. Environmental Research Institute, Hamilton, New Zealand 
29. Department of Biology, University of Hamburg, Hamburg, Germany

30. Ontario Ministry of the Environment, Conservation and Parks, Dorset Environmental Science Centre, Dorset, ON, Canada

31. CNR Water Research Institute, L. go Tonolli 50, Verbania Pallanza, Italy

32. Department of Environmental Science and Policy, University of California, One Shields Ave., Davis, CA, USA

33. Centre d'études nordiques (CEN) and Faculty of Sciences and Engineering, Université Laval, Québec, Canada

34. Eawag, Swiss Federal Institute of Aquatic Science and Technology, Surface Waters Research and Management, Kastanienbaum, Switzerland

35. Department of Ecology, University of Innsbruck, Innsbruck, Austria

36. Vrije Universiteit Brussel, Department of Hydrology and Hydraulic Engineering, Pleinlaan 2, Brussels, Belgium

37. ETH Zurich, Institute for Atmospheric and Climate Science, Universitaetstrasse 16, Zurich, Switzerland

38. National Institute of Water and Atmospheric Research Ltd (NIWA), Gate 10 Silverdale Rd., Hillcrest, Hamilton, New Zealand

39. Cary Institute of Ecosystem Studies, Box AB, Millbrook, New York, USA

40. Biology Department, State University of New York College at Oneonta (SUNY Oneonta), Oneonta, New York, USA 


\section{Summary paragraph:}

84 The concentration of dissolved oxygen in aquatic systems helps regulate biodiveristy ${ }^{1,2}$, nutrient

85 biogeochemistry $^{3}$, greenhouse gas emissions ${ }^{4}$, and drinking water quality ${ }^{5}$. The long-term

86 declines in dissolved oxygen concentrations in coastal and ocean waters have been linked to

87 climate warming and human activity ${ }^{6,7}$, but little is known about changes in dissolved oxygen

88 concentrations in lakes. While dissolved oxygen solubility decreases with increasing water

89 temperatures, long-term lake trajectories are not necessarily predictable. Oxygen losses in

90 warming lakes may be amplified by enhanced decomposition and stronger thermal stratification ${ }^{8}$,

$91{ }^{9}$ or they may increase as a result of enhanced primary production ${ }^{10}$. Here we analyse 45,148

92 dissolved oxygen and temperature profiles from 393 temperate lakes spanning 1941-2017. We

93 find that a decline in dissolved oxygen is widespread in surface and deep-water habitats. The

94 decline in surface waters is primarily associated with reduced solubility under warmer water

95 temperatures, although surface dissolved oxygen increased in a subset of highly-productive

96 warming lakes, likely due to increasing phytoplankton production. In contrast, the decline in

97 deep waters is associated with stronger thermal stratification and water clarity losses, but not

98 with changes in gas solubility. Our results suggest that climate change and declining water

99 clarity have altered the physical and chemical environment of lakes. Freshwater dissolved

100 oxygen losses are 2.5-10 times greater than observed in the world's oceans ${ }^{6,7}$ and could threaten

101 essential lake ecosystem services ${ }^{2,3,5,11}$. 
Main text:

106

The concentration of dissolved oxygen (DO) in aquatic systems influences biodiversity ${ }^{1}$

$107{ }^{2}$, nutrient biogeochemistry ${ }^{3}$, greenhouse gas emissions ${ }^{4}$, drinking water quality ${ }^{5}$, and, ultimately, 108 human health ${ }^{12}$. Many aquatic species require well-oxygenated habitat ${ }^{11,13}$ and cool water to 109 survive warm summers ${ }^{2}, 11$. Loss of deep-water DO degrades water quality by promoting the 110 release of accumulated nutrients from sediments into water ${ }^{1,3}$, which can increase phytoplankton

111 biomass. This process can also facilitate harmful algal blooms ${ }^{5}$, which can compromise water 112 supplies and harm human health ${ }^{12}$. Despite clear evidence of large-scale deoxygenation in ocean 113 waters ${ }^{6,7}$, there are no systematic large-scale studies of this phenomenon in lakes ${ }^{3}$. DO concentrations should decline with increasing water temperature due to reduced gas 115 solubility. However, other mechanisms can alter DO, potentially amplifying or counteracting 116 losses predicted from solubility changes alone. For example, rates of heterotrophic respiration 117 increase with temperature faster than primary production ${ }^{9}$, and surface-temperature warming can 118 increase the strength and duration of thermal stratification, reducing water circulation, and 119 preventing deep-water DO replenishment ${ }^{8,14,15}$. Studies of individual lakes demonstrate deep120 water DO concentrations can decrease with lake warming ${ }^{3,8,15}, 16$, reducing access to cold-water 121 habitat essential to many organisms ${ }^{11}$. However, given the many feedbacks and processes 122 regulating DO, overall trajectories currently defy a priori prediction.

We addressed this critical issue by compiling and analyzing an extensive database of lake 124 temperature and DO profiles to characterize widespread and long-term changes in DO 125 concentration and its causes. We used data from 393 temperate lake and reservoir basins, each 126 with a minimum of 15 years of observation (median: 24 years), and report population medians 127 from long-term surface- (epilimnion) and deep-water (hypolimnion) trends in temperature, DO 
concentration, and DO saturation during the late summer period when seasonal DO depletion is expected to be pronounced ${ }^{17}$. Our analyses revealed that lake DO concentrations have declined in both surface and deep waters from 1980 to 2017 by 0.45 and $0.42 \mathrm{mg} \mathrm{L}^{-1}$, respectively (Fig. 1). These rates represent losses of 5.1 and $20.2 \%$ for surface and deep waters, respectively, and were substantially greater than those observed for the oceans, where total water-column DO has declined about $2 \%$ since $1960^{6}$.

While deep-water temperatures have been virtually stable since observations began (Fig. $1 \mathrm{a} ;-0.01^{\circ} \mathrm{C}$ decade $\left.^{-1}\right)$, both deep-water DO concentration and percent saturation declined through time $\left(-0.12 \mathrm{mg} \mathrm{L}^{-1}\right.$ decade $^{-1}$ and $-1.2 \%$ decade $^{-1}$; respectively, Fig. $\left.1 \mathrm{~b}, \mathrm{c}\right)$. Declines were unrelated to solubility as predicted changes based on solubility (slight increase of $0.01 \mathrm{mg} \mathrm{L}^{-1}$ ) were negligible compared with observed losses (median $-0.23 \mathrm{mg} \mathrm{L}^{-1}$ based on last five years relative to first five years of each time series, Fig. 2b) Declining DO, despite essentially unchanging solubility, implies deep-water habitats have become increasingly inhospitable for organisms with aerobic metabolism, including fishes. We quantified potential impacts of such declines on habitat availability by calculating trends in $T_{\mathrm{DO} 3}$, the minimum water column temperature where DO was at least $3 \mathrm{mg} \mathrm{L}^{-1}$. This metric was developed to quantify oxy-thermal habitats for cold-water fisheries ${ }^{11}$. In lakes where DO was below $3 \mathrm{mg} \mathrm{L}^{-1}$ anywhere in the water column at least once in the time series $(\mathrm{n}=369), T_{\mathrm{DO} 3}$ increased by $0.17^{\circ} \mathrm{C}$ decade $^{-1}$, with $68.0 \%$ of lakes having positive trends and declining habitat for many cold-water species.

In contrast to trends observed for deep waters, variation in surface-water DO concentrations was well explained by changes in gas solubility. Consistent with other globalscale lake studies ${ }^{18}$, median air temperatures warmed at $0.30^{\circ} \mathrm{C}$ decade ${ }^{-1}$ and median lake surface waters warmed at $0.39^{\circ} \mathrm{C}$ decade ${ }^{-1}$. Additionally, median wind speed and precipitation declined 
151 (trends of $-0.04 \mathrm{~m} \mathrm{~s}^{-1}$ decade $^{-1}$ and $-4.23 \mathrm{~mm} \mathrm{decade}{ }^{-1}$, respectively), while shortwave radiation

152 increased $\left(1.88 \mathrm{~W} \mathrm{~m}^{2}\right.$ decade $^{-1}$; Table S1). Surface-water temperature increases were best

153 explained by spring and summer air temperature increases and by summer wind speed declines

154 (Table S2). Surface-water DO concentrations declined at $-0.11 \mathrm{mg} \mathrm{L}^{-1}$ decade $^{-1}$ (Fig. 1b).

155 Comparing the last five years relative to first five years of each time series revealed that the

156 median change predicted due to solubility loss was $\sim 63 \%$ of the median observed decline in DO

157 concentration, with solubility-predicted loss of 0.12 versus observed losses of $0.19 \mathrm{mg} \mathrm{L}^{-1}$ (Fig.

$1582 \mathrm{a})$.

Despite a strong influence of water temperature on DO concentration in surface-waters,

160 there was substantial variability among lakes (Fig. 2a), and a large subset of lakes exhibited

161 increases in both water temperature and DO concentration ( $n=87$; Fig. 3d). Analysis of the

162 interaction between DO concentration, surface temperature, and water clarity (measured as

163 Secchi depth, a proxy for trophic status ${ }^{19}$ ) showed that DO concentration generally decreased

164 with increasing temperature. However, in lakes with low water clarity $(<2 \mathrm{~m})$, DO concentration

165 increased when average mean summer surface-water temperatures exceeded $\sim 24^{\circ} \mathrm{C}$ (Fig. $3 \mathrm{c}$ ).

166 Similarly, in a subset of lakes with chlorophyll data (a proxy for phytoplankton biomass; $\mathrm{n}=$

167 162), positive DO trends were observed when chlorophyll was high and surface temperatures

168 exceeded $\sim 25^{\circ} \mathrm{C}$, (Fig. $3 \mathrm{~b} ; P<0.001$ ). Thus, we suggest that eutrophication and warming interact

169 to increase surface-water DO concentration despite reduced gas solubility.

Lakes with increasing DO concentration in warming surface waters had significantly

171 higher surface-water temperatures (Fig. 3a; $P=0.016$ ) and their watersheds contained a

172 significantly higher proportion of agriculture $(P=0.046)$ and developed land cover $(P<0.001)$

173 compared with other lakes. When developed land exceeded $\sim 50 \%$ of a watershed and surface 
174 water temperature exceeded $\sim 25^{\circ} \mathrm{C}$, the probability of a warming lake having an increasing DO

175 trend was $>50 \%$. Combined, these analyses highlight a potential threshold above which water

176 temperatures and lake productivity interact to elevate DO concentration in surface waters despite

177 declining gas solubility. While we lack data on phytoplankton taxonomic composition, evidence

178 indicates that phytoplankton blooms are increasing globally ${ }^{20}$, in particular due to

179 cyanobacteria ${ }^{21}$. High temperatures and elevated nutrient loading can promote surface

180 cyanobacteria blooms whose photosynthesis leads to DO supersaturation, particularly in

181 eutrophic lakes as temperatures exceed $\sim 23-25^{\circ} \mathrm{C}^{10,21}$. Consistent with this inferred mechanism,

182 we note these same lakes exhibited consistently low deep-water DO concentration (median: 0.64

$183 \mathrm{mg} \mathrm{L}{ }^{-1}$ ) relative to other lakes (median: $3.42 \mathrm{mg} \mathrm{L}^{-1}$ ), as is expected when a large phytoplankton

184 biomass sinks and is decomposed in deep-water habitats ${ }^{22}$. Deep water DO changes are described 185 in more detail below.

Decadal-scale trends in DO were associated with non-linear changes in surface-water

187 temperature (Fig. 2c-f; Fig. S1). For example, although surface-water temperatures generally

188 increased from 1980 onwards, there was a period of accelerated increase during 1990-2000, with

189 slower warming thereafter (Fig. 2c), consistent with the "warming hiatus" observed during 1998-

$1902012^{23}$. This trend occurs across the population of all lakes, as well as the subset of lakes

191 sampled continuously throughout this period. Similarly, surface-water DO exhibited periodic

192 deviations from an overarching trend of declining DO concentration (Fig. 2d), mainly due to the

193 productive lakes exhibiting increasing DO levels in surface waters (Fig. 2d, blue line). Excluding

194 these lakes, analysis of the remaining sites showed a consistent long-term decline in surface-

195 water DO (Fig. 2d, red line). Deep-water temperatures exhibited a pronounced multi-decadal 
oscillation since 1980 (Fig. 2e) as has been observed in some lakes previously ${ }^{24}$, whereas deepwater DO concentration declined consistently through time (Fig. 2f).

While surface-water DO concentration changes were generally well predicted by solubility changes, deep-water DO changes were more strongly associated with changes in water clarity and water-column density differences (Figs. 4 and S2). For example, water clarity losses exceeding $1 \mathrm{~m}$ were associated with substantial reductions in deep-water DO saturation (Fig. S2). Mechanistically, increases in phytoplankton biomass or dissolved organic matter (DOM) reduce water clarity while increasing oxygen-consuming respiration ${ }^{19,22,25}$. Increases in phytoplankton biomass and DOM are often caused by land use change and recovery from acid deposition, respectively ${ }^{26}$. However, there was no overarching decline in water clarity across study lakes. Indeed, $51 \%$ of lakes had clarity increases and $49 \%$ had decreases, and only $39 \%$ of lakes exhibited both water clarity loss and DO saturation loss (Fig. 4a).

Deep-water DO decreased substantially in lakes where the water column density difference between surface and deep waters increased by more than $\sim 0.5 \mathrm{~kg} \mathrm{~m}^{-3}$ (Fig 4b; Fig. S2b). Strong increases in the density difference indicate intensified stratification that reduces vertical mixing and replenishment of deep-water DO from the atmosphere, and may reduce nutrient upwelling to surface waters ${ }^{3,15}$. Water column density differences increase due to water clarity losses as well as other factors that increase heat gain in near-surface waters, including climate warming ${ }^{26}$ and atmospheric stilling ${ }^{27}$. Increased water column density differences may also be associated with earlier onset of seasonal stratification and thus more time for oxygen consumption before the summer sampling period ${ }^{22}$. We found that changes in water-column density differences were best explained by changes in deep water temperature and climate characteristics (Fig. S3). Despite no overarching among-lake trend in water clarity or deep-water 
219 temperature, stratification strength increased in $84 \%$ of lakes that stratified, with $61 \%$ of basins 220 exhibiting both increased density difference and DO saturation loss (Fig 4b). Warming surface221 water temperatures combined with unchanging deep-water temperatures (Fig. 1a) increases the 222 density difference in lake water columns (median rate: $0.10 \mathrm{~kg} \mathrm{~m}^{-3} \mathrm{decade}^{-1}$ ). We observed 223 unchanging deep-water DO in lakes where both clarity and stratification were unchanged (Fig.

224 4c, d). Therefore, we anticipate further DO losses in deep waters of lakes where water clarity 225 continues to decline or thermal stratification intensifies, whether due to atmospheric warming, 226 stilling, or both $26,27$.

228 lake deoxygenation is clear, with climate changes and water clarity losses contributing to 229 declines in lake DO concentration at rates $\sim 2.5-10$ times greater than those observed in the global 230 oceans ${ }^{6,7}$. We find deep-water lake habitats are especially threatened, and deep-water DO trends 231 may portend future losses of cold-water and oxygen-sensitive species ${ }^{2}$, increased internal 232 nutrient loading which exacerbates eutrophication ${ }^{3}$ and the formation of harmful algal blooms ${ }^{5}$, 233 and potentially increased outgassing of stored methane ${ }^{4}$. While already rapid, future losses in 234 lake DO may accelerate due to continued anthropogenic modifications of the environment, 235 including eutrophication ${ }^{22}$, salinization ${ }^{28}$, and hydrological management ${ }^{28}$. While many lakes 236 have undergone active management to reduce nutrient loads, in part to mitigate phytoplankton 237 growth and deep-water oxygen $\operatorname{loss}^{28}$, our findings suggest such actions will likely require more 238 rigorous efforts in the future to counter the effects of climate and land use change. 


\section{References:}

241 1. Wetzel, R. G. 2001. Chap. 9 oxygen. In: Limnology, $3^{\text {rd }}$ edn (ed Wetzel R. G.), pp 151-168, 242 Academic Press, San Diego.

243 244

245 246

247

248

249

250

251

252

253

2. Schindler, D. Warmer climate squeezes aquatic predators out of their preferred habitat. Proc. Natl. Acad. Sci., 114, 9764-9765 (2017).

3. North, R. P., North, R. L., Livingstone, D. M., Köster, O., \& Kipfer, R. Long-term changes in hypoxia and soluble reactive phosphorus in the hypolimnion of a large temperate lake: consequences of a climate regime shift. Glob. Change Biol., 20, 811-823 (2014).

4. Fernández, J. E., Peeters, F., \& Hofmann, H. Importance of the autumn overturn and anoxic conditions in the hypolimnion for the annual methane emissions from a temperate lake. Environ. Sci. Technol., 48, 7297-7304 (2014).

5. Michalak, A. M., et al. Record-setting algal bloom in Lake Erie caused by agricultural and meteorological trends consistent with expected future conditions. Proc. Natl. Acad. Sci., 110, 6448-6452 (2013).

6. Schmidtko, S., Stramma, L., \& Visbeck, M. Decline in global oceanic oxygen content during the past five decades. Nature, 542, 335-339 (2017).

7. Breitburg, D., et al. Declining oxygen in the global ocean and coastal waters. Science, 359, DOI: 10.1126/science.aam7240 (2018).

8. Jankowski, J., Livingstone, D. M., Bührer, H., Forster, R., \& Niederhauser, P. Consequences of the 2003 European heat wave for lake temperature profiles, thermal stability, and 
hypolimnetic oxygen depletion: Implications for a warmer world. Limnol. Oceanogr., 51, 815-819 (2006).

262

263

264

265

266

267

268

269

270

271

272

273

274

275

276

277

278

279

9. Yvon-Durocher, G., Jones, J. I., Trimmer, M., Woodward, G., \& Montoya, J. M. Warming alters the metabolic balance of ecosystems. Philos. T. R. Soc. B, 365, 2117-2126 (2010).

10. Seki, H., Takahashi, Y., Hara, Y., \& Ichimura, S. Dynamics of dissolved oxygen during algal bloom in Lake Kasumigaura, Japan. Water Res., 14, 179-183 (1980).

11. Jacobson, P. C., Stefan, H. G., \& Pereira, D. L. Coldwater fish oxythermal habitat in Minnesota lakes: influence of total phosphorus, July air temperature, and relative depth. Can. J. Fish. Aquat. Sci., 67, 2002-2013 (2010).

12. Harke, M. J., et al. A review of the global ecology, genomics, and biogeography of the toxic cyanobacterium, Microcystis spp. Harmful Algae, 54, 4-20 (2016).

13. Vaquer-Sunyer, R., \& Duarte, C. M. Thresholds of hypoxia for marine biodiversity. Proc. Natl. Acad. Sci., 105, 15452-15457 (2008).

14. Woolway, R. I., \& Merchant, C. J. Worldwide alteration of lake mixing regimes in response to climate change. Nat. Geosci., 12, 271-276 (2019).

15. Livingstone, D. M. Impact of secular climate change on the thermal structure of a large temperate central European lake. Clim. Change, 57, 205-225 (2003).

16. Zhang, Y., et al. Dissolved oxygen stratification and response to thermal structure and longterm climate change in a large and deep subtropical reservoir (Lake Qiandaohu, China). Water Res., 75, 249-258 (2015). 
17. Bouffard, D., Ackerman, J. D., \& Boegman, L. Factors affecting the development and dynamics of hypoxia in a large shallow stratified lake: hourly to seasonal patterns. Water Resour. Res., 49, 2380-2394 (2013).

18. O'Reilly, C. M., et al. Rapid and highly variable warming of lake surface waters around the globe. Geophys. Res. Lett., 42, 10773-10781 (2015).

19. Nürnberg, G. K. Trophic state of clear and colored, soft- and hardwater lakes with special consideration of nutrients, anoxia, phytoplankton and fish. Lake Reserv. Manag., 12, 432-447 (1996).

20. Ho, J. C., Michalak, A. M., \& Pahlevan, N. Widespread global increase in intense lake phytoplankton blooms since the 1980s. Nature, 574, 667-670 (2019).

21. Kosten, S., et al. Warmer climates boost cyanobacterial dominance in shallow lakes. Glob. Change Biol., 18, 118-126 (2012).

22. Müller, B., Bryant, L. D., Matzinger, A., \& Wüest, A. Hypolimnetic oxygen depletion in eutrophic lakes. Environ. Sci. Technol., 46, 9964-9971 (2012).

23. Winslow, L. A., Leach, T. A., \& Rose, K. C. Global lake response to the recent warming hiatus. Environ. Res. Lett., 13, 054005 (2018).

24. Livingstone, D. M. An example of the simultaneous occurrence of climate-driven "sawtooth" deep-water warming/cooling episodes in several Swiss lakes, Verh. Int. Ver. Limnol., 26, 822-828 (1997).

25. Williamson, C. E., et al. Ecological consequences of long-term browning in lakes. Sci. Rep., 5, DOI:10.1038/srep18666, (2015). 
301 26. Rose, K. C., Winslow, L. A., Read, J. S., \& Hansen, G. J. A. Climate-induced warming of 302 lakes can be either amplified or suppressed by trends in water clarity. Limnol. Oceanogr. 303 Letters., 1, 44-53 (2016).

304 27. Woolway, R. I., Merchant, C. J., Van Den Hoek, J., Azorin-Molina, C., Nöges, P., Laas, A., 305 Mackay, E. B., and Jones, I. D. Northern hemisphere atmospheric stilling accelerates lake 306 thermal responses to a warming world. Geophys. Res. Lett., 46, 11983-11992 (2019).

307 28. Carpenter, S. R., Stanley, E. H., \& Vander Zander, M. J. State of the world's freshwater 308 ecosystems: physical, chemical, and biological changes. Annu. Rev. Env. Resour., 36, 75-99

309 (2011). 
312 Acknowledgments: This manuscript benefited from conversations at meetings of the Global

313 Lake Ecological Observatory Network (GLEON; supported by funding from US NSF grants

3141137327 and 1702991). SFJ and KCR acknowledge support from US NSF grants 1638704,

3151754265 , and 1761805 and SFJ was supported by a US Fulbright Student grant to Uppsala

316 University, Sweden. GH acknowledges the many employees of the Minnesota Department of

317 Natural Resources, the Minnesota Pollution Control agency, and citizen volunteers for data

318 collection and collation. PRL acknowledges support from a NSERC Discovery Grant, the

319 Canada Research Chair Program, Canada Foundation for Innovation, the Province of

320 Saskatchewan, University of Regina, and Queen's University Belfast. RLN \& JJ acknowledge

321 support from the Missouri Department of Natural Resources and the Missouri Agricultural

322 Experiment Station and many students that collected and processed reservoir samples under the

323 leadership of Daniel V. Obrecht and Anthony P. Thorpe. RMP and CEW acknowledge support

324 from NSF grants 1754276 and 1950170, Miami University Eminent Scholar Fund, and the

325 Lacawac Sanctuary and Biological Field Station for access to Lake Lacawac and use of research

326 facilities. RIW acknowledges support from the European Union's Horizon 2020 research and

327 innovation programme under the Marie Skłodowska-Curie grant agreement No. 791812. SC

328 acknowledges support of the Castle Lake Research Program through the University of Nevada

329 and UC Davis via Charles R. Goldman. CLD acknowledges the King County Environmental

330 Laboratory for the long-term monitoring data for Lake Washington and Lake Sammamish. JD

331 acknowledges support from the University of Warmia and Mazury in Olsztyn (Grant under the

332 Senate Committee for International Cooperation financing) and staff at Department of Water

333 Protection Engineering for long-term data collection and analysis. OE acknowledges support

334 from the Russian Scientific Foundation (grant 19-77-30004) for Mozhaysk Reservoir. GF 
acknowledges support for long-term sampling of Lake Caldonazzo by the Fondazione Edmund Mach. HPG acknowledges funding for long-term sampling of Lake Stechlin by the Leibniz association and assistance by members of the IGB team. KDH acknowledges the Oklahoma Department of Wildlife Conservation, the Oklahoma Water Resources Board, the Grand River Dam Authority, the US Army Corps of Engineers, the City of Tulsa, W.M. Matthews, T. Clyde, R.M Zamor, P. Koenig, and R. West for support, assistance, and data for Lakes Texoma, Thunderbird, Grand, Eucha, and Spavinaw. JH acknowledges support from the ERDF/ESF project Biomanipulation as a tool for improving water quality of dam reservoirs (No CZ.02.1.01/0.0/0.0/16_025/0007417). BL acknowledges support from the FA-UNIMIB for longterm monitoring of Lake Iseo. EBM acknowledges support from the UK Natural Environment Research Council funding for the long-term monitoring on Blelham Tarn and the staff of the Freshwater Biological Association and UK Centre for Ecology and Hydrology for carrying out the work. AP and JAR acknowledge support from the Ontario Ministry of the Environment, Conservation and Parks for providing data from south-central Ontario lakes ("Dorset lakes") and staff and students at Ontario's Dorset Environmental Science Centre for data collection and analysis. MR acknowledges the International Commission for the Protection of Italian-Swiss Waters (CIPAIS) for funding long-term research on Lake Maggiore. EST acknowledges Prof. Lauren Chapman (McGill University) and her team for the long-term data collection in Lake Nkuruba. MS acknowledges the City of Zurich Water Supply and the cantonal agencies of the cantons of Bern (AWA, Gewässer- und Bodenschutzlabor), Zurich (AWEL), St. Gallen (AFU), and Neuchatel for providing data for the Swiss lakes, CIPEL and INRA for data from Lake Geneva, and IGKB for data from Lake Constance. WT acknowledges support from the Belgian Science Policy Office through the research project EAGLES (CD/AR/02A) on Lake Kivu. PV 
358 acknowledges support from the councils of the regions of Waikato, West Coast, and Bay of

359 Plenty for long-term sampling of lakes Taupo, Brunner, and Tarawera. KY acknowledges

360 support from the Clark Foundation for long-term monitoring of Otsego Lake and past and current

361 members of SUNY Oneonta BFS for sampling. KS and JS acknowledge the National Park

362 Service, W Gawley, Acadia National Park for providing data for Jordan Pond, Bubble Pond, and

363 Eagle Lake in Maine. The views expressed in this article are those of the authors and do not 364 necessarily reflect views or policies of funding agencies.

Authorship contributions: SFJ and KCR designed the study, compiled the data, conducted analyses, and drafted the manuscript. GJAH, BMK, PRL, JLM, RLN, RMP, JTS, CEW and RIW helped design the study and conduct analyses, contributed data, and edited the manuscript. All 369 other authors contributed data, edited the manuscript, or both.

371 Author information: Derived statistics used in our analyses are publicly available via the

372 Environmental Data Initiative (EDI) repository at:

373 https://doi.org/10.6073/pasta/ac8b05bb0da19032b3df3efc21f83874.

374 Reprints and permissions information is available at www.nature.com/reprints. The authors 375 declare no competing interests.

376 Correspondence and requests for materials should be addressed to KCR (rosek4@,rpi.edu). 
Figures and Figure Captions:

379

380

381

382

383

384

385

386

387

388

389

390

391

392

393

394

395

396

397

398

399

Fig. 1 | Trends in dissolved oxygen and temperature. a-c, Density plots of trend magnitudes for a temperature $\left({ }^{\circ} \mathrm{C}\right.$ decade $\left.^{-1}\right), \mathbf{b}$ DO concentration $\left(\mathrm{mg} \mathrm{L}^{-1}\right.$ decade $\left.^{-1}\right)$ and $\mathbf{c}$ DO percent saturation $\left(\%\right.$ decade $\left.^{-1}\right)$. Red distribution indicates surface water trends and blue indicates deepwater trends. The $\mathrm{x}$-axis range for each plot covers two standard deviations from the median, or approximately $95 \%$ of data. Vertical dashed lines indicate median trends, and the zero trend is highlighted with a black vertical line.

Fig. 2 | Solubility effects and changes in temperature and DO concentration through time. a, b, Observed vs. predicted change in DO concentration $\left(\mathrm{mg} \mathrm{L}^{-1}\right)$ due to solubility for surface (a) and deep (b) waters. Solid black line is the 1:1 line and the blue line is loess smoothed, while the gray regions are 95\% confidence intervals. c-f, Smoothed curves of GAMM models, showing deviation from the mean model predictions for selected response variables with year as the predictor variable. Gray regions represent one standard error from the predicted line for c, temperature $\left({ }^{\circ} \mathrm{C}\right)$ and $\mathbf{d}$, DO $\left(\mathrm{mg} \mathrm{L}^{-1}\right)$ through time for surface waters. The red line represents lakes where both surface temperature and DO were increasing $(n=87)$ and the blue line is all other lakes $(\mathrm{n}=332)$. e, Temperature and $\mathbf{f}$, DO for deep waters.

\section{Fig. 3 | Interaction of productivity and temperature in surface waters. a, Predicted}

probability of a lake having both increasing surface temperature and DO concentration from a fitted logistic regression model at three different mean surface water temperatures: $21^{\circ} \mathrm{C}$ (blue), $25^{\circ} \mathrm{C}$ (black), $28^{\circ} \mathrm{C}$ (red) b, Predictions of DO trends from a fitted multiple regression model for 
400 chlorophyll (used as a surrogate for primary productivity) at these same temperatures (legend

401 same as a) c, The interaction of water clarity (measured as Secchi depth in m) and surface-water

402 temperature $\left({ }^{\circ} \mathrm{C}\right)$ and their effects on surface DO $\left(\mathrm{mg} \mathrm{L}^{-1}\right)$ from fitted generalized additive mixed

403 models (GAMM) d, Most lakes exhibited increasing surface temperatures and decreasing DO

404 concentration consistent with solubility effects, but a subset of lakes $(n=87)$ have both

405 increasing surface temperature and DO concentration.

406

407 Fig. 4 | Effect of changes in water clarity and density difference on deep-water DO

408 saturation change. a, Change in \% saturation versus change in water clarity (Secchi depth). b,

409 Change in \% saturation versus change in water column density difference between surface and

410 deep waters. The number of lakes in each quadrant in $\mathrm{a}$ and $\mathrm{b}$ are indicated by text. c, Predictions

411 of change in \% saturation from a fitted multiple regression model for change in water clarity at

412 three density changes. d, Predictions of change in \% saturation from a fitted multiple regression

413 model for change in density difference at three clarity changes. Note that for both c and d the

414 origin sits at no change in either predictor. 
a

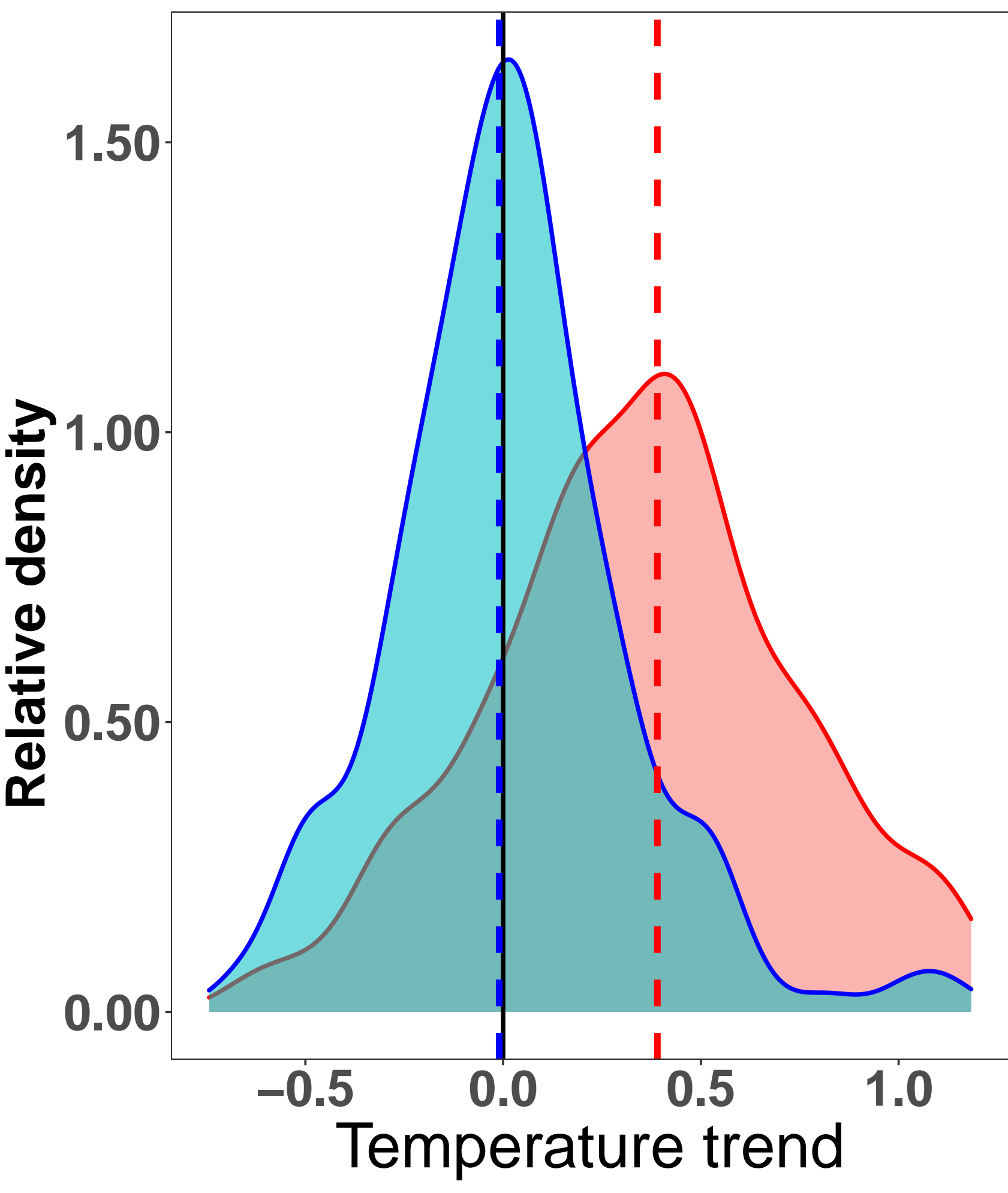

$\left({ }^{\circ} \mathrm{C}\right.$ decade $\left.^{-1}\right)$ b

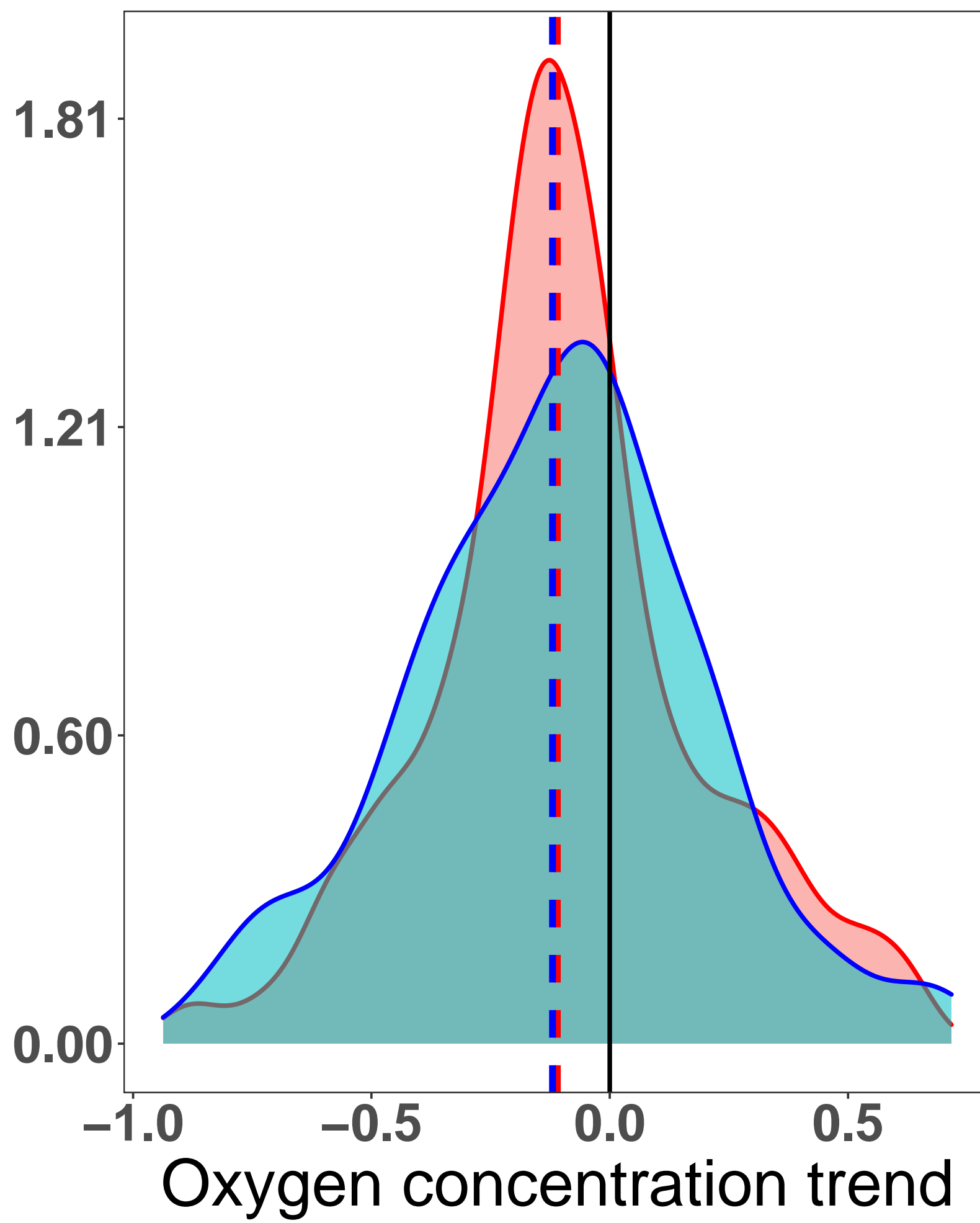
$\left(\mathrm{mg} \mathrm{L}^{-1}\right.$ decade $\left.^{-1}\right)$

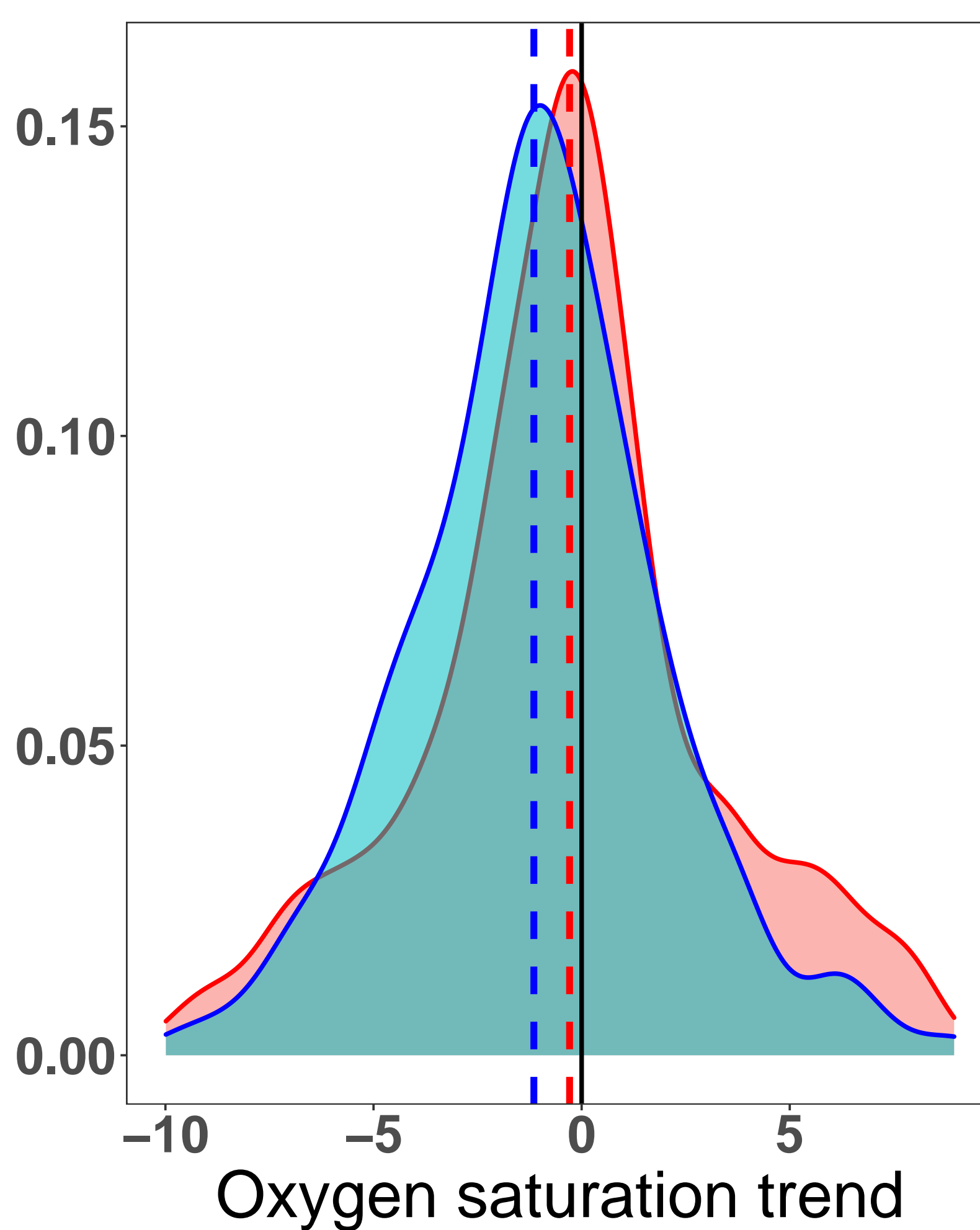

$\left(\%\right.$ decade $\left.^{-1}\right)$ 

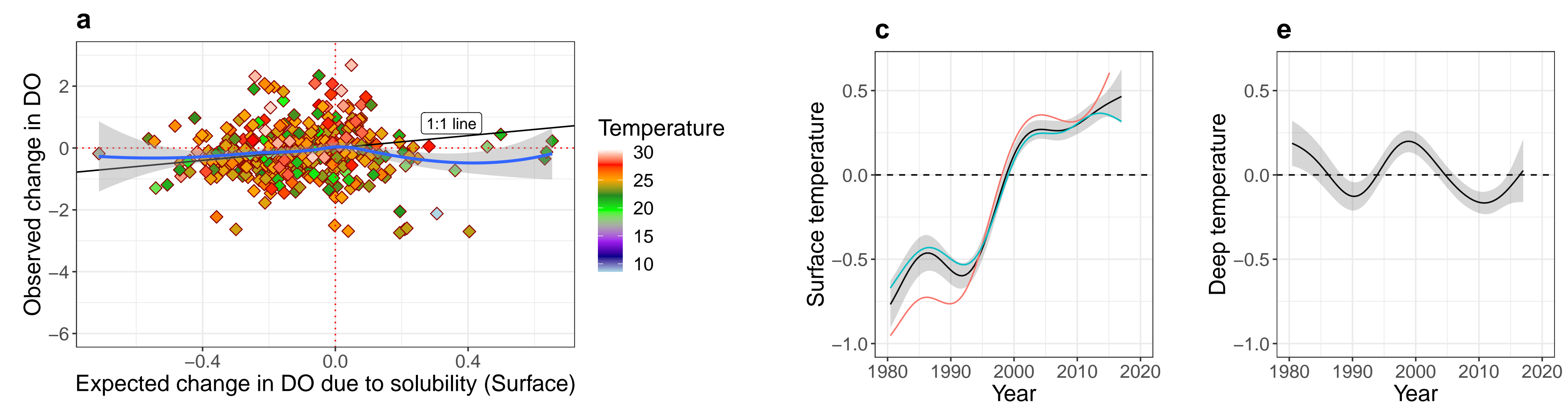

b

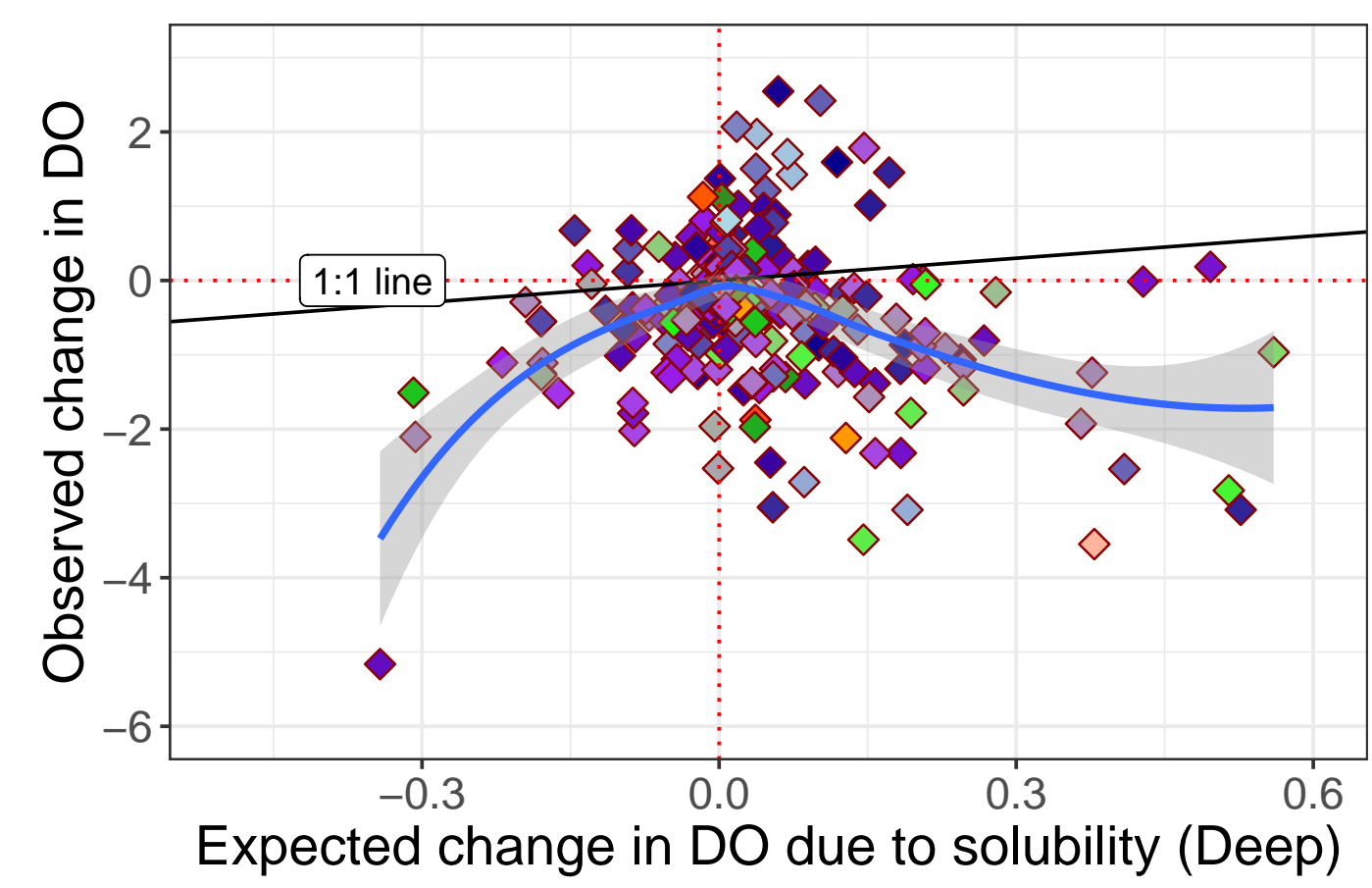

Temperature

25
20
15
10
5
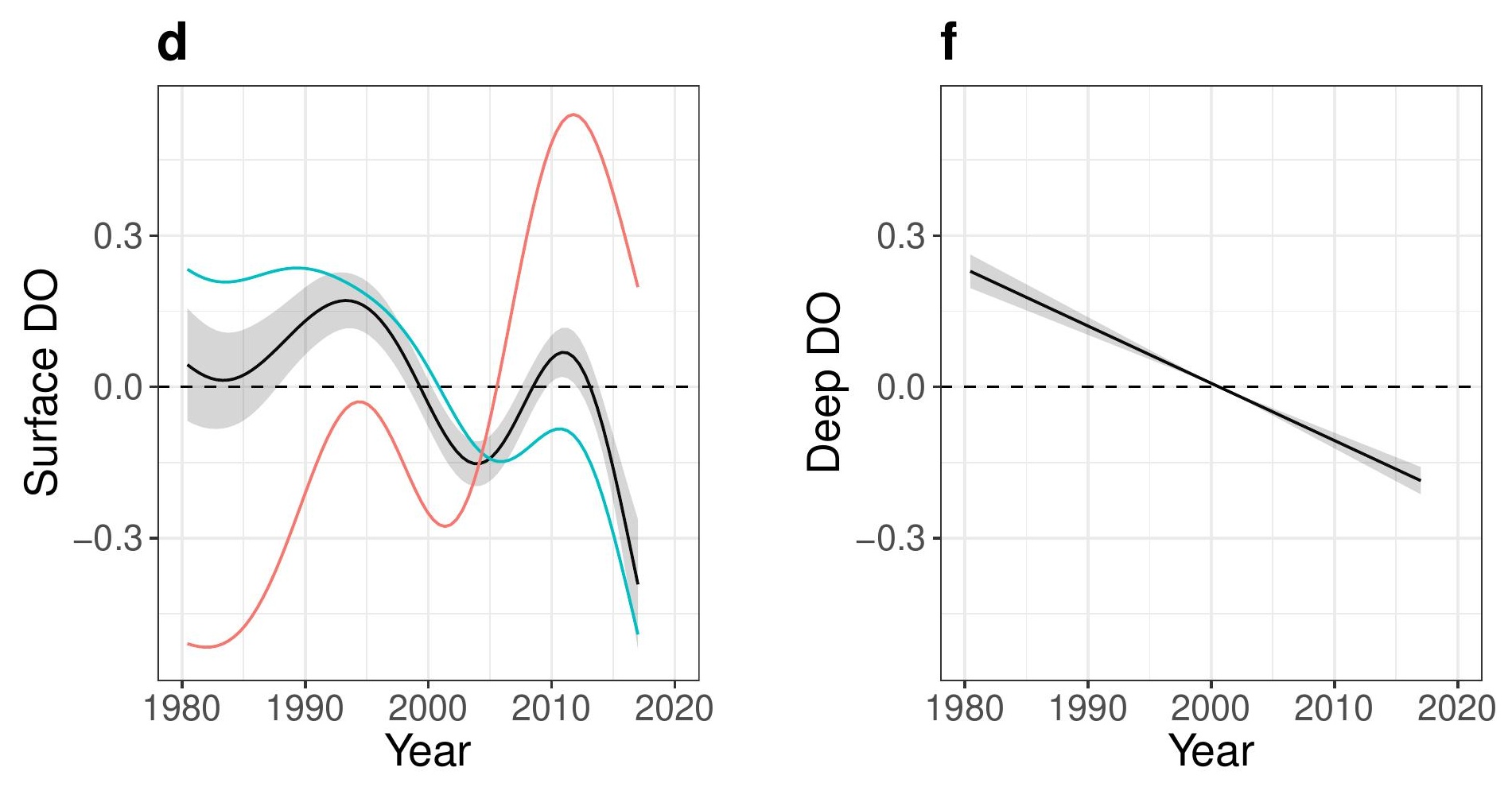


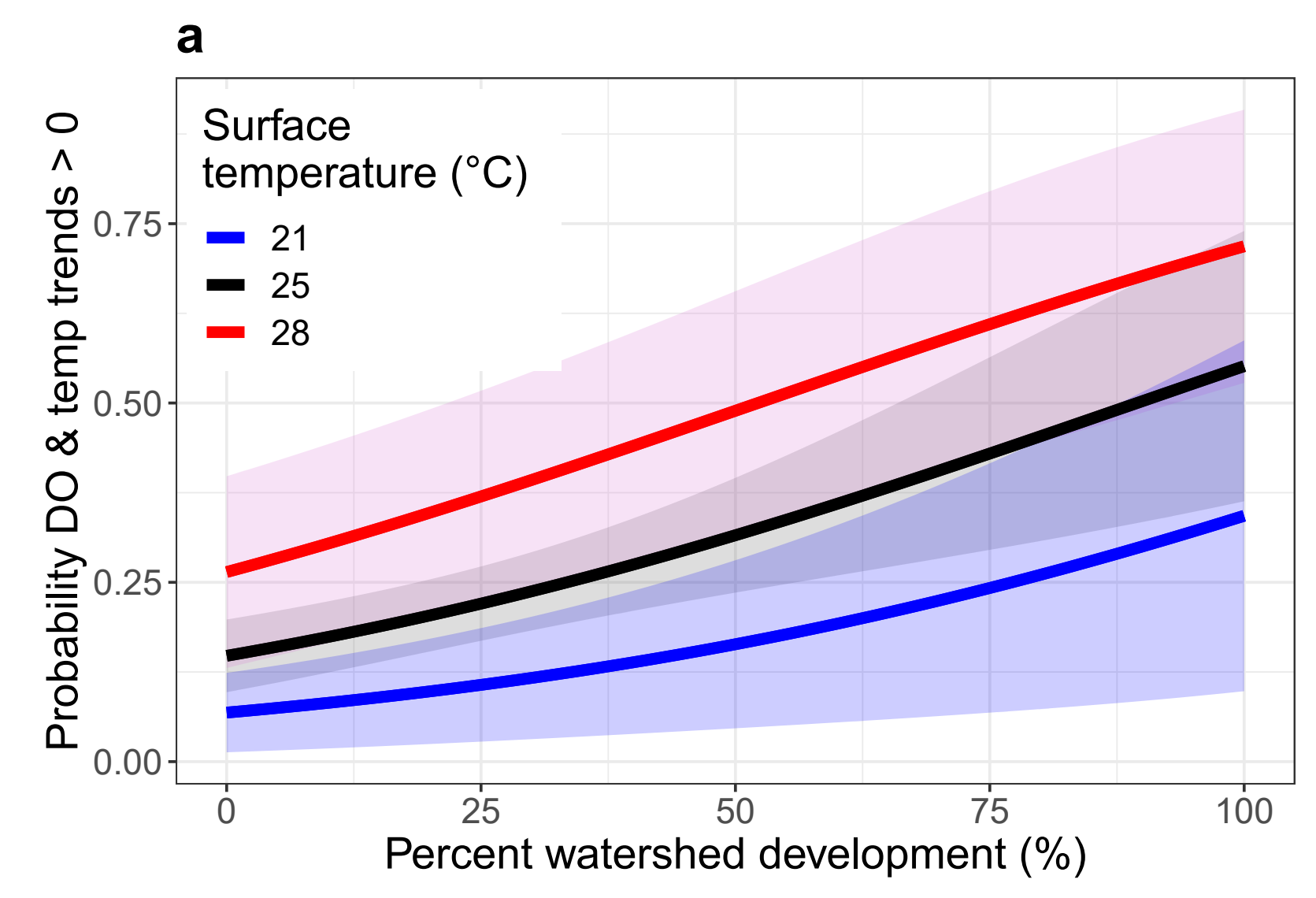

C

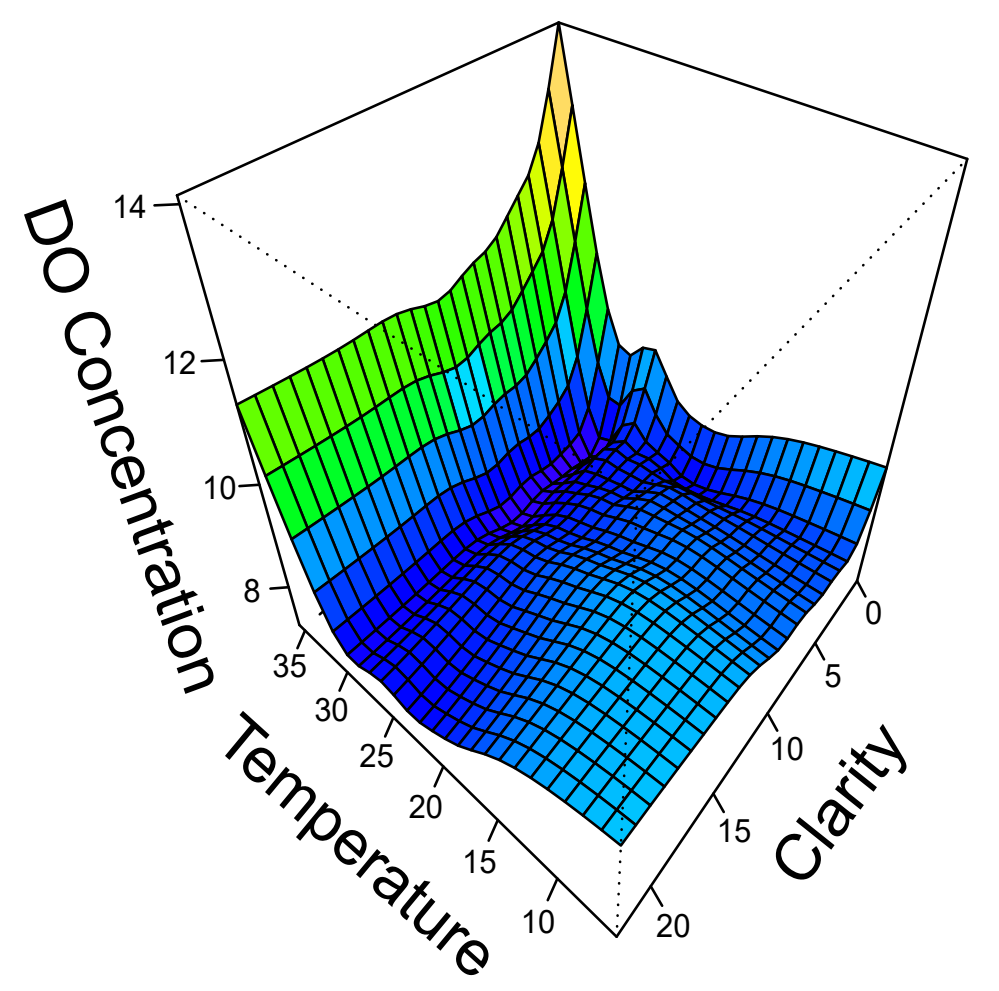

b
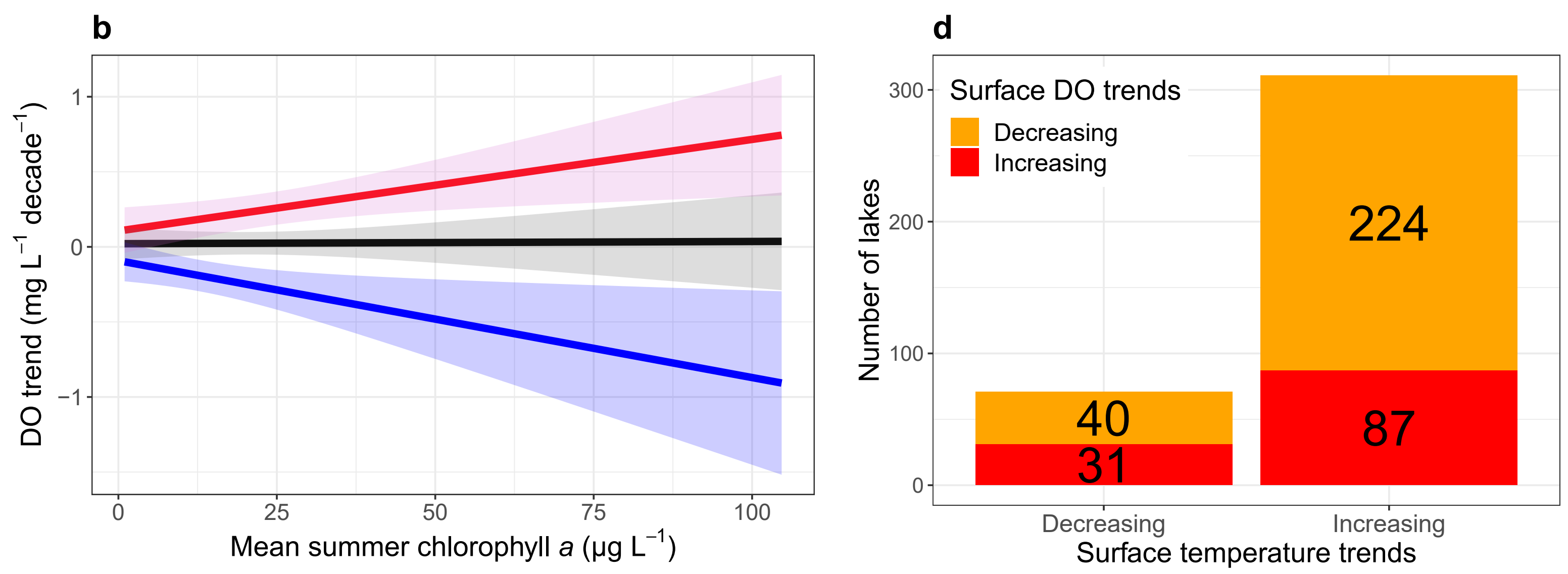

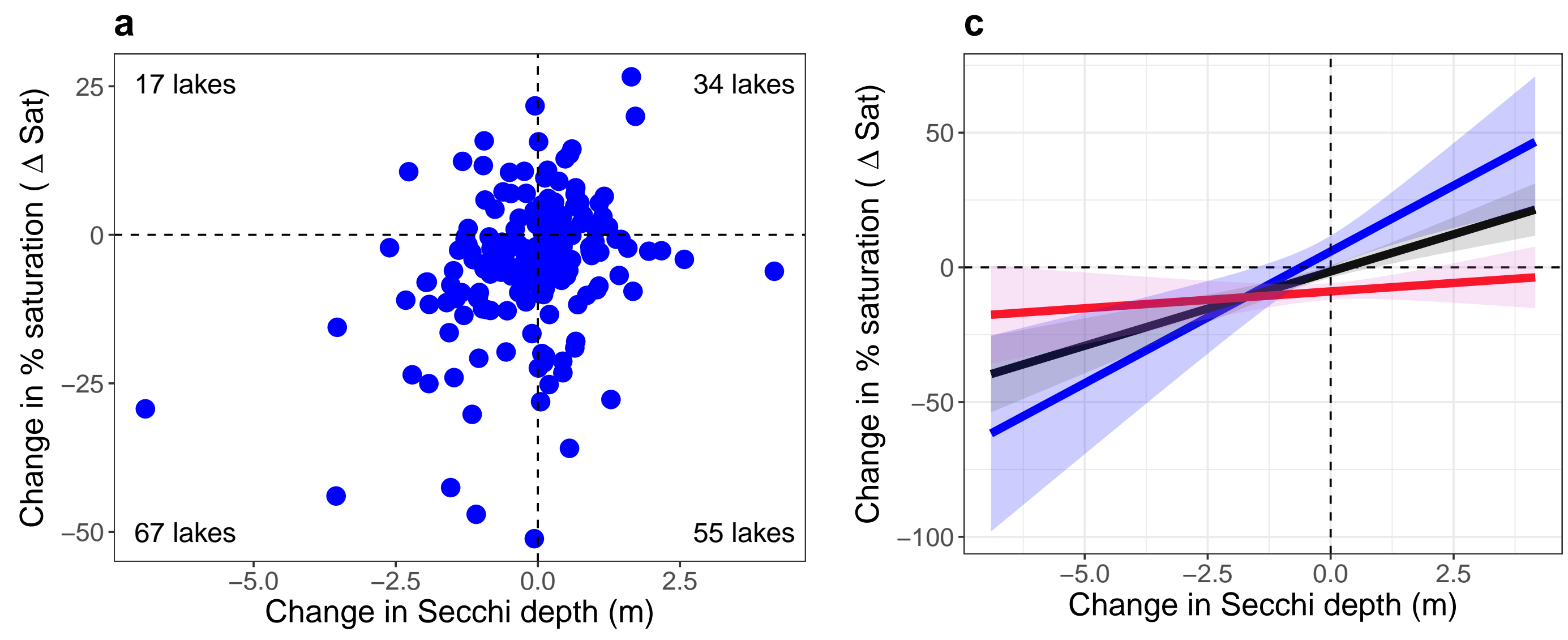

Change in density difference $\left(\mathrm{kg} \mathrm{m}^{-3}\right)$

- -0.7

- 0

- 0.7

b

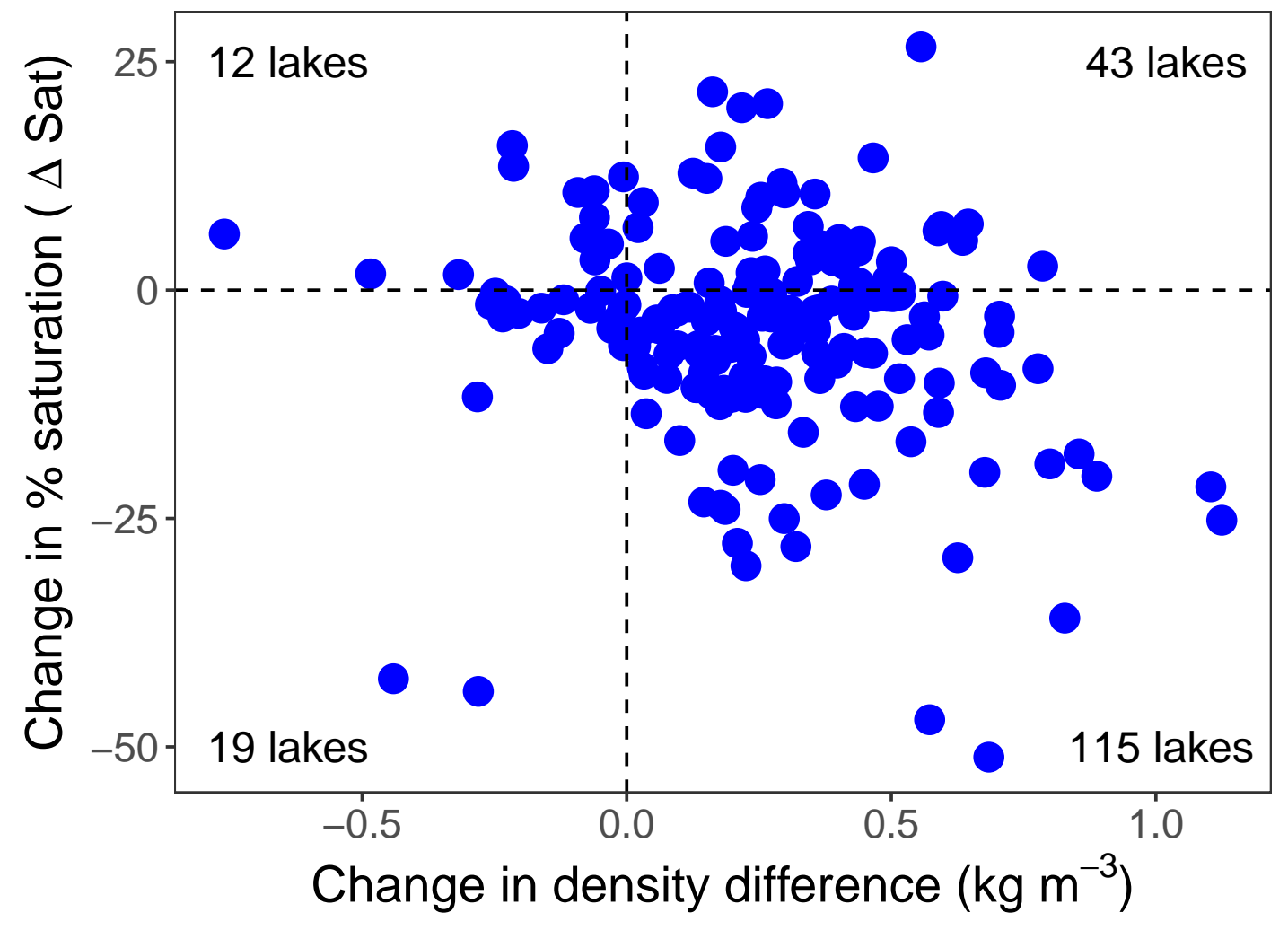

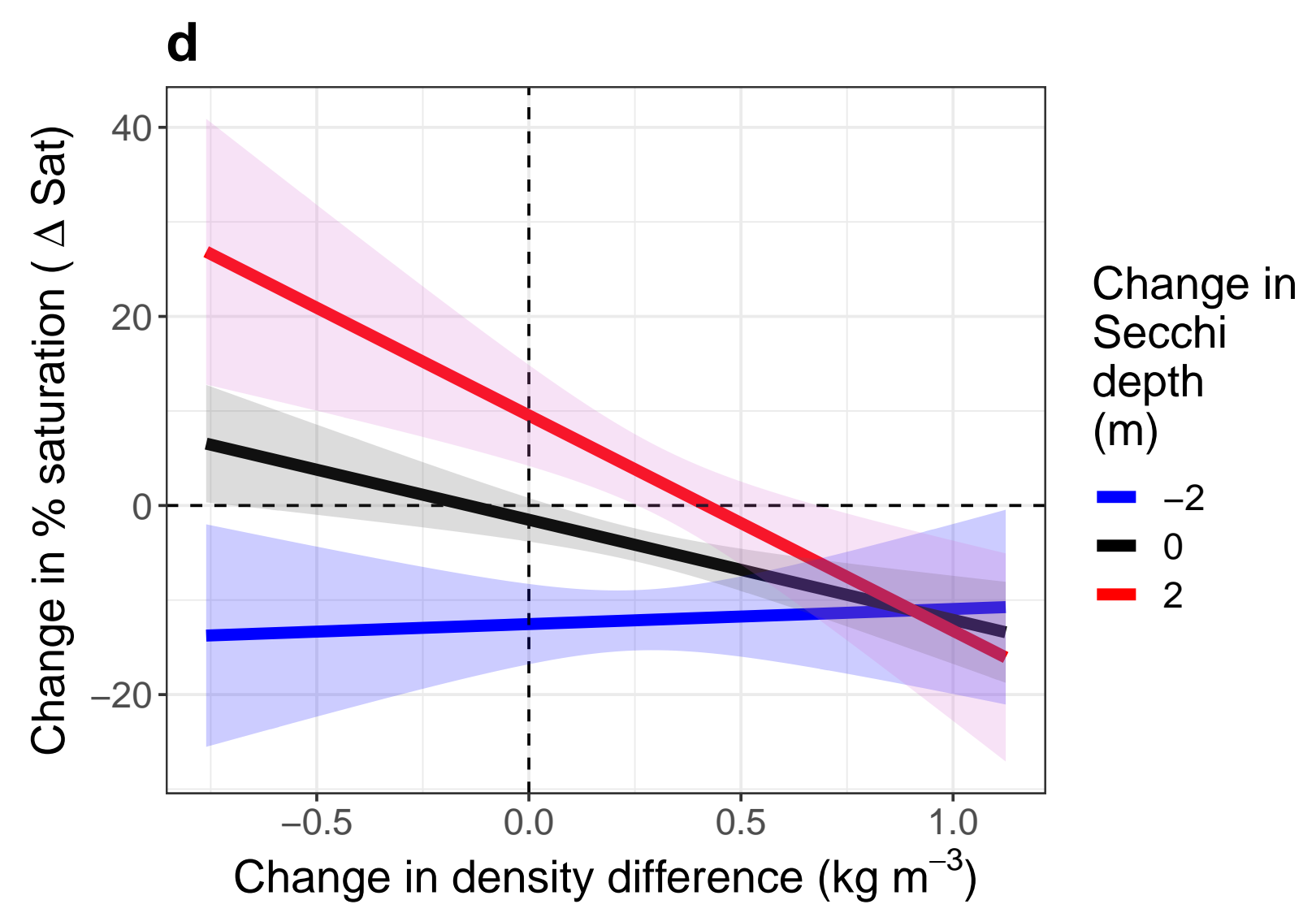




\section{Supplemental information}

There are seven supplemental information tables and four supplemental information

418 figures. Tables S1 and S2 are referenced in text. Table S3 describes data contributors for this 419 project and Table S4 provides location and trend information for each lake. Trend data were not

420 reported for a) two lakes where providers did not provide permission to publish data but that 421 were included in trend analyses (Annecy and Geneva; 'NP' in table S4), b) lakes had less than 15

422 years of data at a given depth (not shown in table), or c) deep-water trends in lakes that did not

423 thermally stratify ('NA' in table S4). In one lake (T Bird), epilimnetic water was artificially 424 aerated and this depth layer was excluded from analysis. Table S5 presents statistics associated 425 with spatial autocorrelation analyses. Table S6 describes trends over the entire population of 426 lakes versus a sub-sample of lakes after accounting for the large numbers of samples obtained in 427 lake-rich regions. Table S7 describes trends and uncertainty in trends over two time periods for 428 subsets of lakes having data for at least 80\% of years: 1980-2017 and 1990-2017. Fig. S1

429 presents the results of GAMM analysis of trends zoomed out to visualize distribution of residuals 430 for surface and deep-water temperature and dissolved oxygen trends. Fig. S2 presents the partial 431 dependency plots for the top predictors of changes in deep-water DO percent saturation as

432 determined by a random forest analysis. Fig. S3 presents partial dependency plots for the top 433 predictors of changes in water column density difference between surface and deep waters as 434 determined by a random forest analysis. Fig. S4 presents the locations of lakes used in this study $435 \quad(n=393)$. 
437 Figure S1 | Results of GAMM analysis of trends zoomed out to visualize distribution of

438 residuals. a, Surface-water temperature $\left({ }^{\circ} \mathrm{C}\right) \mathbf{b}$, Deep-water temperature $\left({ }^{\circ} \mathrm{C}\right)$ c, Surface-water

439 DO (mg L $\left.{ }^{-1}\right)$ and $\mathbf{d}$, Deep-water DO concentration $\left(\mathrm{mg} \mathrm{L}^{-1}\right)$.

$441 \quad$ Figure S2 | a-f, Partial dependency plots from a random forest algorithm of deep-water change 442 in \% dissolved oxygen saturation ( $\Delta$ Sat) in the last five years of record relative to the first five 443 years of record for each lake. Plots are ordered by predictor variable importance, decreasing in 444 importance from the upper left to lower right (a to f). Vertical red lines indicate zero change in 445 predictor variable and hash marks on the $\mathrm{x}$-axis indicate lake distribution deciles. Partial 446 dependencies indicate the relationship between predictor and response variables when holding 447 other variables at their mean value. Lakes that experienced no change in either water clarity or 448 density difference between surface and deep waters exhibited little change in deep-water 449 saturation (see also, Fig. 4).

Figure S3 | Drivers of the change in density difference between surface and deep waters. a-f,

452 Partial dependency plots from a random forest algorithm of deep-water change in water column 453 density difference in the last five years of record relative to the first five years of record for each 454 lake. Plots are ordered by predictor variable importance, decreasing in importance from the 455 upper left to lower right (a to f). Vertical red lines indicate zero values for predictor variable and 456 hash marks on the $\mathrm{x}$-axis indicate lake distribution deciles. Partial dependencies indicate the 457 relationship between predictor and response variables when holding other variables at their mean 458 value. 
460 Fig. S4 | Locations of lakes used in this study (n=393).

461 

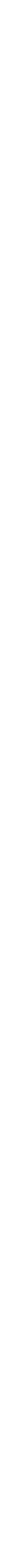

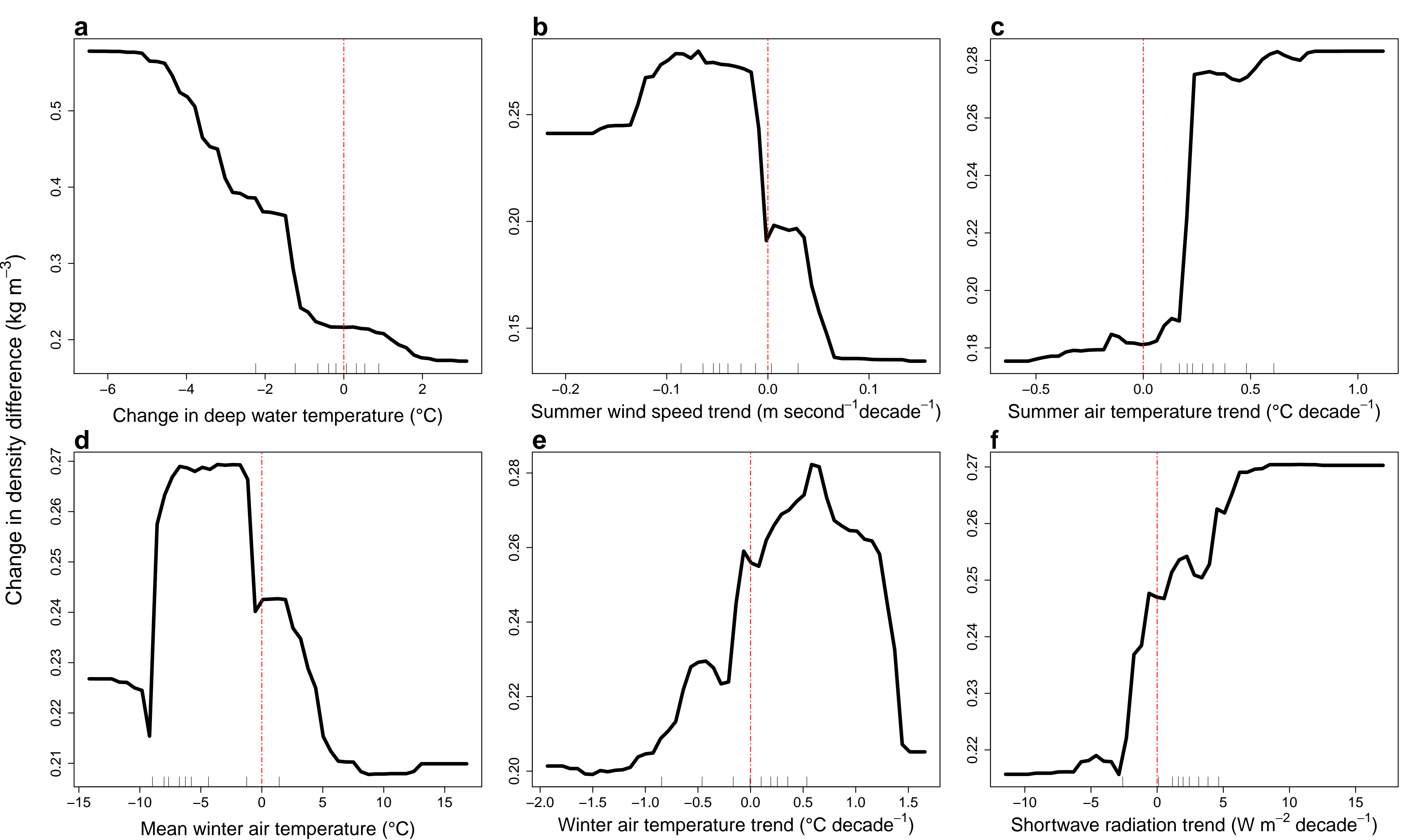


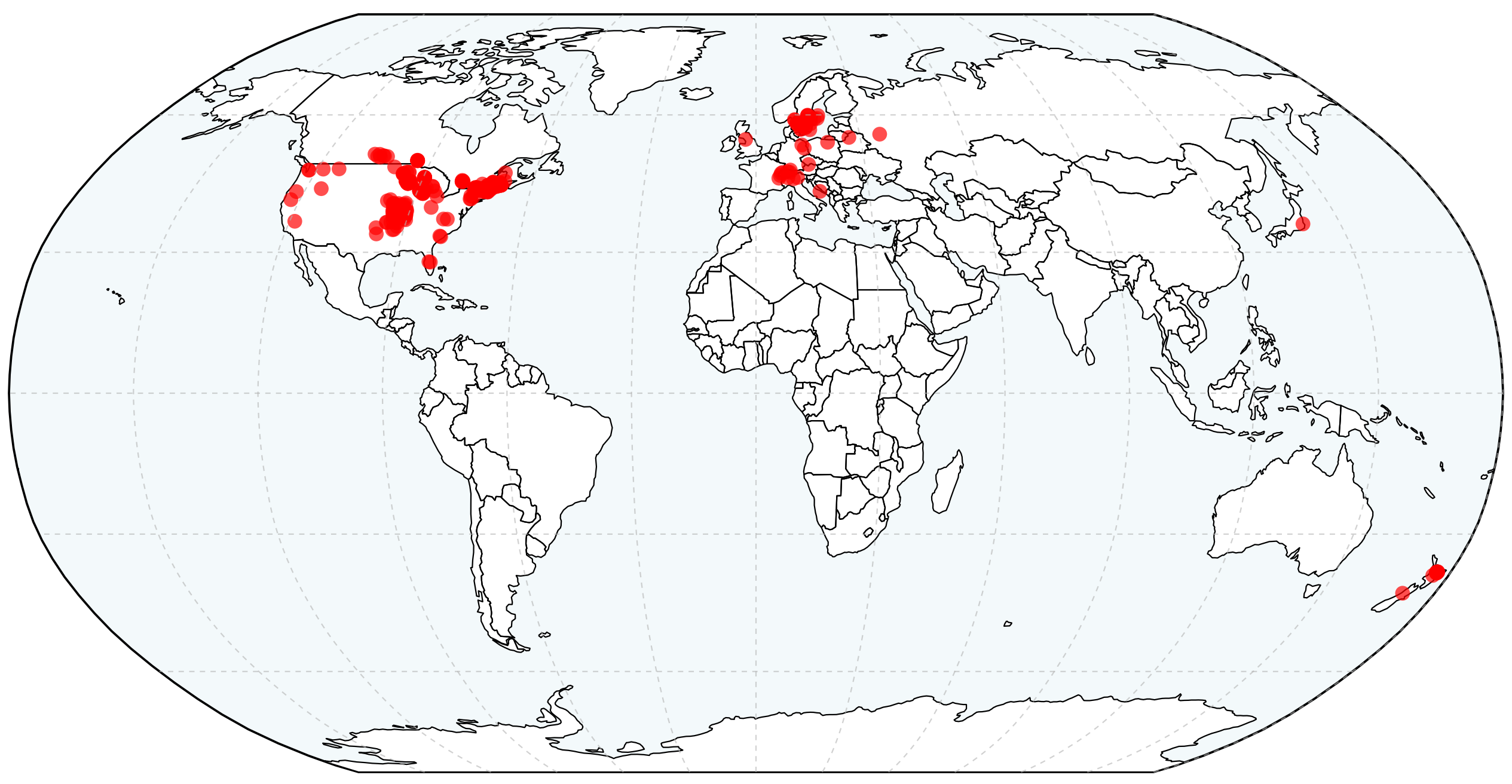


Methods:

463

\section{Overview}

Our methods here describe how we 1) compiled and quality-checked data, 2) interpolated

465

466

467

468

469

470

471

472

473

474

475

476

477

478

479

480

481

482

483

and delineated water layer strata, and 3) statistically analyzed these data. Our statistical analyses

focused on characterizing long-term trends in climate characteristics (air temperature, wind speed, precipitation, and short-wave radiation), DO concentration and saturation, water temperature, and deep-water habitat quality; identifying and characterizing potential nonlinearity in DO concentration and water temperature through time; characterizing the relationship between DO concentration changes and solubility, chlorophyll, and land use; identifying the predictors of changes in deep-water DO saturation, and characterizing meteorological drivers of surface temperature trends. These methods are described in detail in the sections below.

\section{Data compilation and quality control}

We compiled lake temperature and DO concentration water column measurements from a wide range of government, university, and not-for-profit sources (Fig. S4 and Tables S3 and S4).

To assess long-term trends in temperature and DO concentration, we required profiles be made at least once annually during the peak summertime stratification (defined as the late summer period, July 15 - August 31 for northern hemisphere lakes and January 15 - February 28 for southern hemisphere lakes) offshore (e.g., nearest the deepest location in each lake) for at least 15 years. In some larger lakes ( $n=6$ lakes), we used profiles from two separate locations if the lake had more than one distinct basin and treated these as separate waterbodies. For some analyses other than long-term trend analyses we included lake time series data less than 15 years long, but always at least 10 years in duration (described below). 
We conducted quality control on the compiled data as follows. We first removed

485

486

487

488

489

490

491

492

493

494

495

496

497

498

499

500

501

502

503

504

505

506 impossible values, defined as those outside the range $0-40$ for both temperature (units: ${ }^{\circ} \mathrm{C}$ ) and

DO concentration (units: $\mathrm{mg} \mathrm{L}^{-1}$ ). We then removed profiles from consideration if our initial

quality control step process removed greater than $95 \%$ of the profile or if the profile had less

than three distinct depth points. To reduce the potential impacts of DO measurements made

when sensors sat on or in sediments, we removed the deepest measurement for individual

profiles if the maximum depth for that profile exceeded the maximum depth of $90 \%$ of the

remaining profiles for a given lake.

Not all profiles surveyed the entire water column. Some lakes had some profiles where the shallowest depth was greater than 0 (meaning near-surface measurements were not made), yet temperature measurements showed the nearest surface measurements were within the epilimnion. In these cases, we made the assumption of uniform DO and temperature from the surface to the shallowest measurement and added a $0 \mathrm{~m}$ depth point. We did this by either 1) changing the minimum depth in the profile to 0 if it was less than $0.5 \mathrm{~m}, 2$ ) adding a 0 depth point and assigning temperature and DO values equal to that of the minimum depth point if the minimum depth point was greater than or equal to $0.5 \mathrm{~m}$ but less than or equal to $3 \mathrm{~m}$. If the minimum depth was greater than $3 \mathrm{~m}$, we excluded the profile from analyses. If there were multiple values of either temperature or DO for a given depth, the mean value at this depth was used. These operations and all further analyses were conducted in R version 3.4.2 29 .

In total, the above QA steps removed 2,040 profiles out of a total of 25,023 (8.2\%). After processing and removing eight non-temperate lakes, we had 22,574 DO profiles with corresponding temperature profiles. There was a median of 2.1 profiles per year (range: $1-38$ ) and 23 years of data per lake (see also, Table S4). 


\section{Profile interpolation and strata delineation}

508

509

510

511

512

513

514

515

516 517 considered stratified).

518

519

520

521

522

523

524

525

526

527

528

In order to generate a dataset with consistent depth resolution within and among lakes, we interpolated each temperature and DO profile from depth $0 \mathrm{~m}$ to the deepest depth of each profile at intervals of $0.5 \mathrm{~m}$ using the pchip function of the $\mathrm{R}$ package pracma ${ }^{30}$. This interpolation procedure preserves the overall shape of the profile by preventing overshooting of data values ${ }^{30}$. Following interpolation, we calculated temperature and stability characteristics using the R package rLakeAnalyzer ${ }^{31}$. We delineated the epilimnion and hypolimnion using the meta.depths function $($ slope $=0.1$, seasonal $=$ FALSE), which calculates the top and bottom depths of the metalimnion ${ }^{31}$. If the range of temperatures through the profile is less than $1^{\circ} \mathrm{C}$, the meta.depths function does not return values for the metalimnion (i.e., the profile is not

Many lakes did not have a well-defined hypolimnion. To identify those with a hypolimnion, we first removed lakes where the meta.depths function failed to calculate a bottom metalimnion depth for more than $10 \%$ of profiles. We then calculated the mean of the maximum profile depths across all profiles for each lake, to get a mean profile depth for the lake. If the mean value of the bottom of the metalimnion for a lake was shallower than the calculated mean profile depth for that lake, it was considered to have a hypolimnion. We defined "surface waters" as all depths shallower than or equal to the top metalimnetic depth and "deep waters" as all depths deeper than the bottom depth of the metalimnion.

\section{Characterizing trends in dissolved oxygen and temperature}

We calculated the mean surface- or deep-water temperature and DO concentration and percent saturation. For each lake, we calculated the mean of surface- or deep-water DO 
529 concentration or temperature for all profiles in a given year (in our defined late-summer period)

530 to obtain a mean annual value. We then calculated the percent DO saturation from temperature,

531 DO concentration, and lake elevation data ${ }^{32}$. Mean annual surface- and deep-water temperature

532 and DO concentration measurements were then used to calculate long-term trends for surface

533 waters ( $n=393$ lakes; median number of years per lake: 24$)$ and deep waters $(n=260$; median

534 number of years: 24). All trends were calculated using the nonparametric Sen's slope in the R

535 package openair ${ }^{33}$. For trend analysis, we only used lakes with at least 15 years of data.

$536 \quad$ For deep-water trends, lakes that were essentially anoxic (average hypolimnetic DO $<0.5$

$537 \mathrm{mg} \mathrm{L}^{-1}$ ) had trend magnitudes that clustered near 0 relative to other lakes. This was not

538 unexpected as lakes with essentially no hypolimnetic DO have little potential to lose additional

539 DO. When calculating median trends and for graphical depiction of trends (Fig. 1), we removed

540 these lakes $(n=69 ;$ difference $=191)$.

541 We conducted several analyses to examine the potential of variability in lake data

542 through time (i.e., not all lakes sampled all years of observation) or variability in space (i.e.,

543 some regions sampled much more heavily than others) to influence overall population level

544 trends (see following sections and Tables S5-S6).

545 Spatial autocorrelation and effects of lake clusters

546 Because the lakes included in this study were not uniformly dispersed over all continental

547 land masses, we examined the potential of large numbers of lakes in relatively concentrated

548 regions to drive overall patterns. To do this, we first examined spatial autocorrelation in trends in

549 lake temperature and dissolved oxygen concentration using Moran's I in the R package lctools ${ }^{34,}$

55035 . This statistic ranges from -1 for data that are perfectly dispersed to +1 for data that are 
551 perfectly autocorrelated. Values near zero suggest randomly distributed data. We observed weak

552 but significant spatial autocorrelation in some variables (Table S5; Moran's I values ranging 0.02

553 to 0.27$)$.

554 Following this analysis, we examined the potential for the large numbers of lakes in some

555 regions to dominate overall trends we reported. We tested for potential bias by examining trends

556 for a subset of lakes. We identified four regions in the US with high numbers of lakes (Maine =

557113 lakes, New Hampshire = 38 lakes, Missouri = 41 lakes, and Minnesota = 84 lakes). For each

558 of these clustered regions, we randomly subsampled $10 \%$ of the lakes. After this random

559 subsetting, we found that the overall trends are similar to the trends obtained from all lakes (see

560 Table S6). These results demonstrate that our observed population-level trends are not driven

561 solely by trends observed in our lake-rich regions. While our analysis focuses on temperate

562 lakes, we obtained data from a small number of non-temperate lakes $(n=8)$. Including these non-

563 temperate lakes in our analysis (Table S6) did not change our overall results.

\section{Uncertainty estimates and temporal variation in trends}

We conducted an analysis to compare trends, confidence intervals, and significance of

566 trends over two time periods: 1980-2017 $(\mathrm{n}=80)$ and 1990-2017 $(\mathrm{n}=197)$ to assess whether

567 different lake observation years influenced the overall trends in DO concentration and

568 temperature we observed. For each time period, we used a subset of lakes that had data for at

569 least $80 \%$ of years within the defined time period. Following established methods ${ }^{18}$, we

570 calculated a yearly anomaly in temperature and dissolved oxygen for each lake as the difference

571 between each year's observation and the long-term mean. We then averaged these anomalies

572 across all lakes and used linear regression to calculate the slope, significance, and confidence

573 intervals of these averaged anomalies (Table S7). 


\section{Characterizing trends in climate characteristics}

575

576

577

578

579

580

581

582

583

584

585

586

587

588

We examined trends in air temperature, total precipitation, wind speed, and shortwave radiation using the ERA-5 reanalysis from the European Centre for Medium-Range Weather Forecasts $(\mathrm{ECMWF})^{36}$. This data set provides a single gridded global product with a resolution of $0.25^{\circ}$ latitude by $0.25^{\circ}$ longitude over the period $1979-2019$ available as monthly averages (air temperature, wind speed, and shortwave radiation) or totals (precipitation). We used ECMWF time-series data from the gridded location closest to each lake and over the two-month period around when lakes were sampled (July-August for Northern hemisphere lakes, January-February for Southern hemisphere lakes). We calculated temporal trends in mean summer air temperature, mean summer wind speed, summer total precipitation, mean summer shortwave radiation, mean winter air temperature, mean spring air temperature, mean fall air temperature using the same methods we used to examine lake temperature and DO trends (see above). We then conducted a multiple regression analysis to assess which of these predictor variables (trends in air temperature, total precipitation, wind speed, or shortwave radiation) best explained surface-water temperature trends.

\section{Trends in climatic variables over the temperate zone}

We delineated gridded latitude and longitudes at $2^{\circ}$ intervals across the entire temperate zone over land masses only as well as over large regions, including Asia (defined by longitude $\geq$ $29.3^{\circ}$; latitude $23.5^{\circ}$ to $60^{\circ}$ ) Europe and North America (longitude $<29.3^{\circ}$; latitude $23.5^{\circ}$ to $60^{\circ}$ ), South America and western Africa (longitude $<0^{\circ}$; latitude $\leq-23.5^{\circ}$ to $-60^{\circ}$ ); and southern Africa, Australia, and Oceania (longitude $\geq 0^{\circ}$; latitude $-23.5^{\circ}$ to $-60^{\circ}$ ). We then used data from the ERA-5 reanalysis (see 'Characterizing trends in climate characteristics' in Methods for details) to calculate trends in climate variables over each of these regions (Table S1). 
Multiple regression analysis of drivers of surface water temperature trends

598

599

600

601

602

603

604

605

606

607

608

609

610

611

612

613

614

615

616 617 DO went below $3 \mathrm{mg} \mathrm{L}^{-1}$ at least once.

We conducted a multiple regression analysis of the meteorological drivers of observed surface water temperature trends. Predictors in the analysis included: summer air temperature trend, summer total precipitation trend, summer wind speed trend, summer shortwave radiation trend, winter air temperature trend, spring air temperature trend, fall air temperature trend, and mean winter temperature (as a proxy for ice cover ${ }^{18}$ ). We z-score standardized all variables to facilitate comparison of model coefficients across variables having different units ${ }^{37}$. We verified that multicollinearity was not a problem by checking that the variance inflation factor was well below ten for all variables ${ }^{38}$. We used the leaps $\mathrm{R}$ package to select subset models including all predictors and two-way interactions, and selected the fitted model having the lowest $\mathrm{AIC}^{39}$.

Coefficients and p-values for the selected model appear in Table S2.

\section{Characterizing trends in deep-water habitat quality}

We used $T_{\mathrm{DO} 3}{ }^{11}$ to quantify trends in oxythermal habitat relevant for cold-water organisms. $T_{\mathrm{DO} 3}$ represents the minimum temperature in the water column where DO concentration was greater than or equal to $3 \mathrm{mg} \mathrm{L}^{-1}$ and has been used to describe habitat availability for cold-water fisheries ${ }^{11}$. To calculate trends in $T_{\mathrm{DO} 3}$ we excluded lakes where the DO concentration was higher than $3 \mathrm{mg} \mathrm{L}^{-1}$ across all depths in all profiles. For the remaining lakes, we calculated $T_{\mathrm{DO} 3}$ for each profile. If a given profile did not have DO below $3 \mathrm{mg} \mathrm{L}^{-1}$, we assigned it the minimum temperature in the profile. We then calculated an annual mean $T_{\mathrm{DO}}$ for the late summer period and excluded lakes that had $\leq 15$ years of data. This left 369 lakes where 
We conducted a generalized additive mixed model (GAMM) analysis to characterize

620

621

622

623

624

625

626

627

628

629

630

631

632

633

634

635

636

637

638

639 640 year fixed effect. overall response of lake temperature and DO concentration through time and to identify any nonlinearity. GAMMs fit a smooth function of the predictor variables showing the relationship of the predictors to the response variable ${ }^{40}$. We conducted separate analyses for four response variables, surface-water temperature, surface-water DO concentration, deep-water temperature, and deepwater DO concentration. For each GAMM, our only predictor variable was the year, resulting in models that show the change in the response variable through time. We used the gamm4 function of the gamm4 package to fit these models using the default thin plate spline for smooth terms ${ }^{41}$. Gamm4 uses penalized regression splines of moderate rank for the smooth function. For two of these models we used a normal error distribution. Because residuals for the deep-water temperature analysis were skewed, we used a gamma distribution. Residuals in the deep-water DO analysis were also skewed, but because there were a large number of 0 values we used a Tweedie distribution instead of a gamma distribution. We limited this analysis to data from 1970 and later and included all lakes with data in the specified time period (total lake $n=419$ ). To account for the non-independent nature of the repeated measurements through time within each individual lake, the slope and intercept were allowed to vary randomly by lake ${ }^{42}$.

We next conducted a GAMM to understand how surface water DO concentration responded to temperature and productivity $(n=419$ lakes $)$. We used Secchi disk depth as a surrogate for productivity ${ }^{19}$. We included fixed effects of mean summer surface water temperature, mean Secchi depth, and the interaction of these two terms in the model. We included a random intercept and slope by year within each lake and included a corresponding 
To determine the relative importance of solubility in explaining changes in DO

643

644

645

646

647

648

649

650

651

652

653

654

655

656

657

658

659

660

661

662

663

664 concentration, we calculated the expected change in DO concentration due to solubility alone and compared this amount to the observed DO change. To do this, we first calculated the difference between the observed mean DO concentration across the last five years and the first five years of record for each lake, requiring a minimum of ten years of data per lake $(n=415$ lakes for surface (Fig. 2a); $n=259$ lakes for deep (Fig 2b)). We then calculated the expected change due solely to solubility and compared observed to expected DO changes. Specifically, we calculated the mean percent saturation in the first five years by first calculating the mean DO saturation for each water column layer (surface or deep waters) and then calculated the mean of all of these values. We then used an analogous approach to calculate mean temperature, DO concentration, and mean DO concentration at 100\% saturation in the last five years of record for each lake. Once we calculated these values, we multiplied the mean DO concentration at $100 \%$ saturation by the decimal value of percent saturation in the first five years of record. This product represents the expected DO concentration if the percent saturation in the last five years of record remained the same as it was in the first five years of record. In other words, we removed the effect of temperature so that if all changes were due solely to solubility, observed changes in DO concentration would be identical to this value.

\section{Relationship between dissolved oxygen trends and chlorophyll}

We used multiple regression to test if chlorophyll concentration and surface-water temperature were predictors of lakes having both increasing surface DO concentration and temperature trends. We first calculated the long-term mean late-summer surface-water (epilimnetic) chlorophyll concentration, which was available for 162 lakes having at least ten years of chlorophyll measurements. We next predicted DO concentration trends using 
chlorophyll and mean surface-water temperature as independent variables. We first fit the linear regression models, starting with a full model that included the interaction of chlorophyll and temperature. We then fit all subset models and selected the model with the lowest AIC value ${ }^{43}$. Using this selected model, we predicted DO concentration trends at three different mean epilimnetic temperatures $\left(21,25\right.$, and $\left.28^{\circ} \mathrm{C}\right)$ across the observed values for chlorophyll.

\section{Relationship between dissolved oxygen trends and land use}

We used logistic regression to better understand the drivers of increasing DO concentration in lakes with increasing surface-water temperatures, using land use/land cover data to model the probability of this phenomenon ${ }^{44}$. Logistic regression predicts the probability of a binary response outcome for different values of predictor variables. Predictors in our logistic regression included the percent of agriculture and developed land cover in the watershed and the mean surface-water temperature over the last ten years of record because these land use characteristics have been associated with increased growth of some phytoplankton taxa in warmer lakes ${ }^{5,21}$. Our binary response was: either a lake had both increasing surface temperature and DO concentration (1) or it did not (0). We tested for all two-way interactions and all main effects. We used the National Land Cover Database 2011 to derive land cover metrics for US lakes $^{45}$. We considered any land falling into any of the developed classes as developed (Developed - Open Space, Developed - Low Intensity, Developed - Medium Intensity, Developed - High Intensity). We tested the goodness of fit of the final model using the HosmerLemeshow test, available in the ResourceSelection R package (function hoslem.test) ${ }^{46}$. This test showed an acceptable goodness of fit $(P=0.166)$. The final number of lakes for analysis that had both land cover data and sufficient data to calculate trends was 326 .

\section{Identifying the predictors of changes in deep-water DO saturation}


We first used a random forest algorithm to obtain predictors of the observed change in percent saturation (i.e., drivers beyond pure solubility effects) in deep waters ${ }^{47}$. We used the percent increase in mean squared error as a measure of predictor variable importance. We conducted the random forest algorithm analysis using the randomForest package ${ }^{48}$. For each analysis, we only used lakes that had no missing values for any of the predictor variables $(\mathrm{n}=$ 693224 lakes).

For the random forest algorithm, the response variable was the change in mean DO 695 percent saturation in the last five years of record relative to the first five years of record for each 696 lake ( $\Delta$ Sat). A positive $\Delta$ Sat indicated an increase in percent saturation while a negative $\Delta$ Sat 697 indicated a decrease in percent saturation. Predictor variables included mean hypolimnetic DO 698 percent saturation, DO concentration, temperature, and thickness of the hypolimnion (ln transformed), mean Secchi depth, In of mean lake depth, log10 of residence time, change in 700 hypolimnetic thickness, change in hypolimnetic temperature, change in Secchi depth, and change in the density difference between surface and deep waters. Mean lake depth and residence time were obtained from the HydroLakes Database ${ }^{49}$. We calculated the density difference across the water column using rLakeAnalyzer to calculate densities for each interpolated depth point in 704 each water column profile ${ }^{31}$. If a given profile was stratified, we then used the mean epilimnetic 705 density and the mean hypolimnetic density and calculated the difference between these densities. 706 If a given profile was not stratified, we took the mean density across the top two meters and the mean density across the bottom two meters and calculated the difference between these densities.

708 We also included trends in the following ERA-5 meteorological variables: summer, fall, and 709 winter air temperature, summer shortwave radiation, and summer wind speed. Finally we 710 included mean winter air temperature as a proxy for ice cover ${ }^{18}$. 
Following the above analysis, change in the density difference between surface and deep

712

713

714

715

716

717

718

719

720

721

722

723

724

725

726

727

728

729

730

731

732

733

waters came out as an important predictor. Although this could be explained by increased surface water temperatures driven by meteorological variables, it is possible that other changes, such as water clarity ${ }^{25}$, could also explain changes in density difference. To disentangle the drivers of changes in water column density differences, we conducted another RF using the same predictor variables as the above analysis but changing the response variable to the change in the density difference. We did not include the response variable from the first analysis ( $\Delta$ Sat). The six most important variables are presented in Fig. S3.

Based on results of the RF analysis, we conducted a multiple regression analysis to predict change in percent saturation $(\Delta$ Sat) for different levels of predictor variables (ln of mean lake depth, change in the density difference across the water column, and change in Secchi depth). We used a subset of lakes where mean deep-water DO concentration exceeded 0.5 mg/L to avoid lakes with little potential to lose DO. Predictor variables were selected because they were the three most important variables identified by RF, except we substituted ln mean lake depth for ln deep layer thickness. This substitution was made because models using ln of deep layer thickness demonstrated substantial non-linearity in plots of residuals against fitted values. Models built with ln mean lake depth greatly improved these patterns and these two variables were correlated $(r=0.51)$. We first fit the multiple regression models starting with a full model that included all predictors and two-way interaction terms. We then fit all subset models and selected the model with the lowest AIC value ${ }^{43}$. Using this selected model, we predicted $\Delta$ Sat at three different values of each of the two predictors change in Secchi depth $(\mathrm{P}<0.001)$ and change in water column density difference $(\mathrm{P}<0.001)$, with $\ln$ mean lake depth held at the median value. 
Data Availability:

736 Many of the datasets analyzed during this study are publicly available on-line and associated

737 links can be found in supplementary Table S3. Derived statistics are publicly available via the

738 Environmental Data Initiative (EDI) repository at

739 https://doi.org/10.6073/pasta/ac8b05bb0da19032b3df3efc21f83874. Most lakes are included

740 here, but we note that due to the collaborative nature of this project and a wide range of data

741 provenance, it was not possible to include every lake in this repository. Data not otherwise

742 already publicly available are available upon request from the corresponding author pending

743 permission from the appropriate data provider.

744

745

\section{References:}

746 29. R Core Team. R: a language and environment for statistical computing. $\mathrm{R}$ foundation for 747 statistical computing, Vienna, Austria (2017).

748 30. Borchers, H. W. pracma: Practical Numerical Math Functions. R package version 2.1.5

749 https://CRAN.R-project.org/package=pracma (2018).

750 31. Winslow, L. A., et al. rLakeAnalyzer: Lake Physics Tools. R package version 1.11.4.

751 https://CRAN.R-project.org/package=rLakeAnalyzer (2017).

752 32. Winslow, L. A., et al. LakeMetabolizer: An R package for estimating lake metabolism from

753 free-water oxygen using diverse statistical models. Inland Waters, 6, 622-636 (2016).

754 33. Carslaw, D. C., \& Ropkins, K. Openair - An R package for air quality data analysis. Environ.

755 Model. Softw., 27-28, 52-61 (2012). 
34. Moran, P. A. P. The interpretation of statistical maps. J. Roy. Stat. Soc. B Met., 10, 243-251 (1948).

35. Kalogirou, S. lctools: Local Correlation, Spatial Inequalities, Geographically Weighted Regression and Other Tools. R package version 0.2-7. https://CRAN.Rproject.org/package=lctools (2019).

36. Copernicus Climate Change Service (C3S). ERA5: Fifth generation of ECMWF atmospheric reanalyses of the global climate. Copernicus Climage Change Service Climate Data Store (CDS), Accessed 10/1/2019. https://cds.climate.copernicus.eu/cdsapp\#!/home

37. Gelman, G., \& Hill, J. Data Analysis Using Regression and Multilevel/Hierarchical Models. Cambridge University Press, New York (2007).

38. Quinn, G. P., \& Keough, M. J. Experimental Design and Data Analysis for Biologists. Cambridge University Press, Cambridge, U. K. (2002).

39. Lumley, T. leaps: Regression Subset Selection (based on Fortran code by Alan Miller). R package version 3.1. https://CRAN.R-project.org/package=leaps (2020).

40. Wood, S. N. Generalized Additive Models: An Introduction with R ( $2^{\text {nd }}$ edition). CRC Press. Boca Raton, FL (2017).

41. Wood, S., \& Scheipl, F. gamm4: Generalized Additive Mixed Models using 'mgcv' and 'Ime4'. R package version 0.2-5. https://CRAN.R-project.org/package=gamm4 (2017).

42. Pinheiro, J. C., \& Bates, D. M. Mixed Effects Models in S and S-Plus. Springer, New York (2000). 
776 43. Burnham, K. P., Anderson, D. R., \& Huyvaert, K. P. AIC model selection and multimodel 777 inference in behavioral ecology: some background, observations, and comparisons. Behav. 778 Ecol. Sociobiol., 65, 23-35 (2011).

779 44. Hosmer, D. W., \& Lemeshow, S. Applied Logistic Regression (2 ${ }^{\text {nd }}$ edition). John Wiley and $780 \quad$ Sons, Inc., New York (2000).

781 45. Homer, C. G., et al. Completion of the 2011 National Land Cover Database for the 782 conterminous United States - Representing a decade of land cover change information. 783 Photogramm. Eng. Remote Sensing, 81, 345-354 (2015).

784 46. Lele, S. R., Keim, J. L., \& Solymos, P. ResourceSelection: Resource Selection (Probability) 785 Functions for Use-Availability Data. R package version 0.3-2. https://CRAN.Rproject.org/package $=$ ResourceSelection (2017).

787 788 789 790 791 792 793 794
47. Cutler, D. R., et al. Random forests for classification in ecology. Ecology, 88, 2783-2792, (2007).

48. Liaw, A., \& Wiener, M. Classification and regression by randomForest. $R$ News, 2, 18-22 (2002).

49. Messager, M. L., Lehner, B., Grill, G., Nedeva, I., \& Schmitt, O. Estimating the volume and age of water stored in global lakes using a geo-statistical approach. Nat. Commun., 7, 13603, doi:10.1038/ncomms1360 (2016). 